\title{
WestVirginiaUniversity
}

THE RESEARCH REPOSITORY @ WVU

Graduate Theses, Dissertations, and Problem Reports

2009

\section{Assessing the variation of driver distraction with experience}

\author{
Nagaanupama Akuraju \\ West Virginia University
}

Follow this and additional works at: https://researchrepository.wvu.edu/etd

\section{Recommended Citation}

Akuraju, Nagaanupama, "Assessing the variation of driver distraction with experience" (2009). Graduate Theses, Dissertations, and Problem Reports. 2033.

https://researchrepository.wvu.edu/etd/2033

This Thesis is protected by copyright and/or related rights. It has been brought to you by the The Research Repository @ WVU with permission from the rights-holder(s). You are free to use this Thesis in any way that is permitted by the copyright and related rights legislation that applies to your use. For other uses you must obtain permission from the rights-holder(s) directly, unless additional rights are indicated by a Creative Commons license in the record and/ or on the work itself. This Thesis has been accepted for inclusion in WVU Graduate Theses, Dissertations, and Problem Reports collection by an authorized administrator of The Research Repository @ WVU. For more information, please contact researchrepository@mail.wvu.edu. 


\title{
ASSESSING THE VARIATION OF DRIVER DISTRACTION WITH EXPERIENCE
}

\author{
Nagaanupama Akuraju
}

Thesis submitted to the

College of Engineering and Mineral Resources

at West Virginia University in partial fulfillment of the requirements

for the degree of

Master of Science
in
Civil Engineering

Leonel Medellin, Ph.D., Chair

David R. Martinelli, Ph.D.,

Martin Pietrucha, Ph.D.

Department of Civil \& Environmental Engineering

Morgantown, West Virginia

2009

Keywords: driver distraction, experience, gender, distraction factors, eye tracking, eye glance, center of roadway 


\section{ABSTRACT \\ ASSESSING THE VARIATION OF DRIVER DISTRACTION WITH EXPERIENCE}

\section{NAGAANUPAMA AKURAJU}

Driver distraction has been a major concern in highway safety. Driver distraction is related to crashes and crash rate varies with age. Driving experience obviously increases with age. The purpose of this study is to determine the relation between driver experience and distraction. The study measures the distraction levels of various drivers and assesses the variation in distraction based on experience and also gender.

Distraction was defined as looking away from the center of the roadway for more than 2 seconds. Factors like distraction duration, percent time spent looking at the center of roadway and number of glances away from the center were considered in the analysis. The distraction factors were measured using a faceLAB eye tracking system. A statistical analysis was carried to test the significance of the variation. No significant statistical difference was observed in the percent time spent at the center of roadway and the number of glances away from the center based on driver experience and gender. A statistically significant difference was observed in the number of glances made by each group of drivers. Experienced drivers made more glances away from the center compared to less experienced drivers and the number was higher for female drivers than male drivers.

The analysis leads to conclusion that though the distraction level does not vary by experience, more experienced drivers exhibit better scanning of the roadway environment. No difference was observed in the distraction between male and female drivers. However, female drivers exhibited better scanning patterns than male drivers in the absence of additional distracting factors. 


\section{ACKNOWLEDGEMENTS}

Firstly, I thank my advisor Dr. Leonel Medellin and Dr. David R. Martinelli, for giving me the opportunity to work with them and for their guidance throughout this work. I would also like to express my sincere gratitude for their kindness, support and encouragement.

I am very grateful to Dr. Martin Pietrucha for accepting to serve on my thesis committee and for his valuable suggestions and comments on my thesis.

I would also like to acknowledge my family members for their encouragement. Especially, my father Mr. Venkateswara Rao, and my mother Mrs. Surya Kumari for their love, affection and support. I would like to thank my brothers Mr. Ravi Kiran, Mr. Ratna Deep and my sisters-in-law Mrs. Indrani and Mrs. Rachana for their support and being with me for everything during the course of my education. I appreciate my family for their ability to make me laugh even in my tough times and bringing balance to my life.

I wish to thank my graduate friends who have been a pleasure to be with throughout these years. It was great to have such kind, lovable and enjoyable friends. I wish them all good luck in their careers and hope to continue this relation with them in the future.

Finally, I would thank MAUTC and WVDOH for funding this research.

Thank you all. 


\section{TABLE OF CONTENTS}

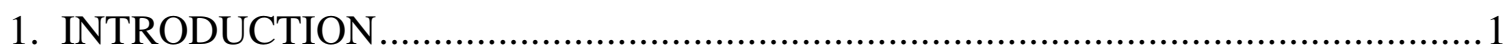

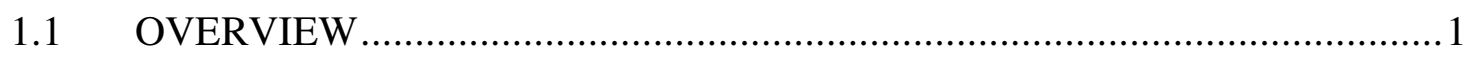

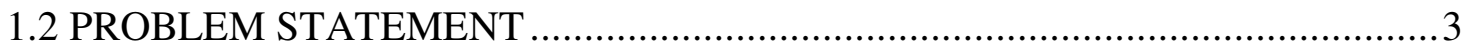

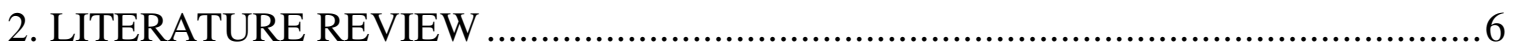

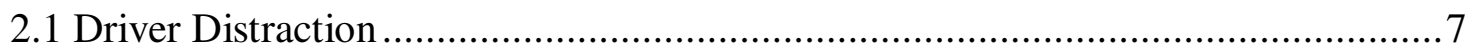

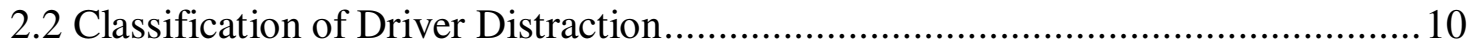

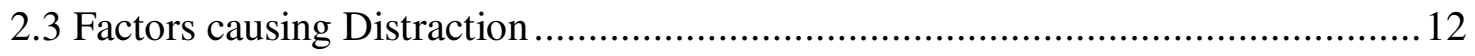

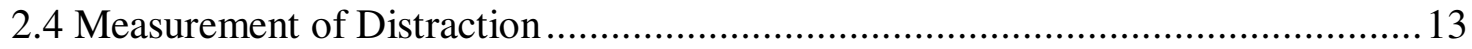

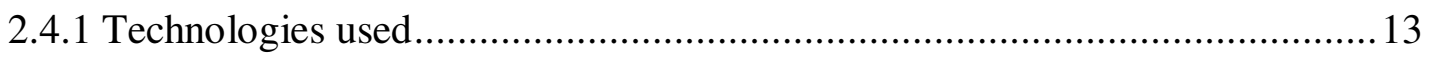

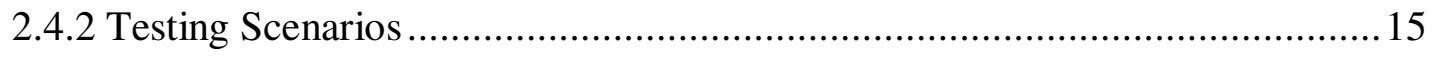

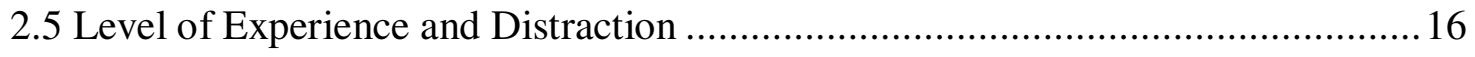

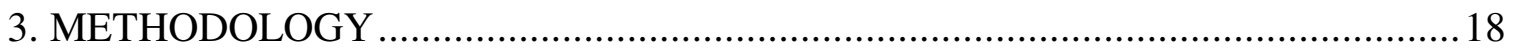

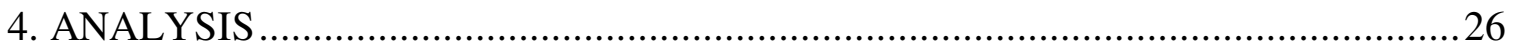

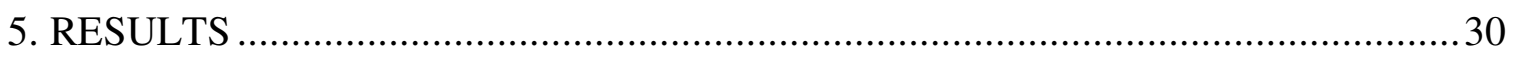

5.1 Total Distraction Duration by Driving Experience …............................................. 31

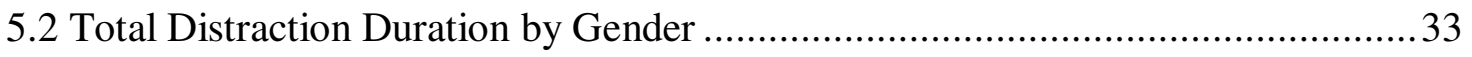

5.3 Percent Time Spent Looking at COR by Driving Experience .................................35

5.4 Percent Time Spent Looking at the COR by Gender .............................................37

5.5 Number of Glances away from COR by Driving Experience..................................39

5.6 Number of Glances away from the COR by Gender ...........................................4

5.7 Percent Time Spent Looking at COR by Driving Experience (Groups 1, 2 and 3) 43

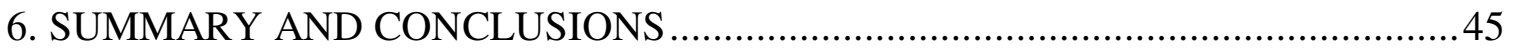


7. RECOMMENDATIONS AND FUTURE RESEARCH ..................................50

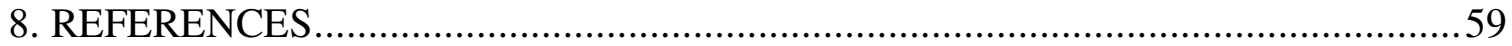




\section{LIST OF FIGURES}

Figure No. 1: Variation of fatality rates with age group .......................................

Figure No. 2: Frame work of the concepts in Driving Task ................................... 8

Figure No. 3: MATLAB code for Traffic Signal Count .........................................28

Figure No. 4: FORTRAN code for Total Distraction Duration................................29

Figure No. 5: Comparison of Total Distraction Durations by Driving Experience .........32

Figure No. 6: t-test results for Total Distraction Duration by Driving Experience .........32

Figure No. 7: Comparison of Total Distraction Duration by Gender .........................34

Figure No. 8: t-test results for Total Distraction Duration by Gender .............................. 34

Figure No. 9: Comparison of Percent Time Spent Looking at COR by Driving

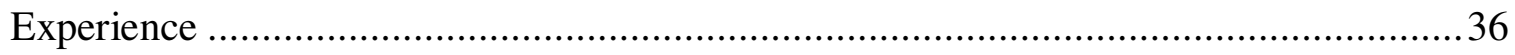

Figure No. 10: t-test results for Percent Time Spent Looking at COR by Driving

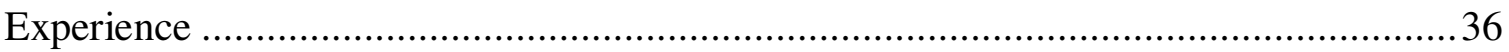

Figure No. 11: Comparison of Percent Time Spent Looking at COR by Gender ...........38

Figure No. 12: t-test results for Percent Time Spent Looking at COR by Gender ..........38

Figure No. 13: Comparison of the Number of Glances by Driving Experience..............40

Figure No. 14: t-test results for Number of Glances by Driving Experience ................. 40

Figure No. 15: Comparison of Number of Glances by Gender ................................42

Figure No. 16: t-test results for Number of Glances by Gender ............................. 42

Figure No. 17: Comparison of Percent Time Spent Looking at COR by Driving

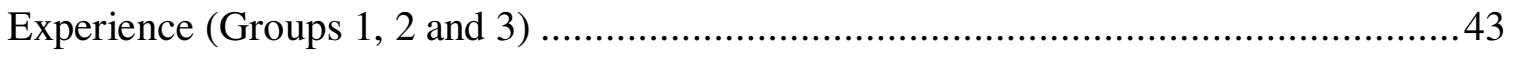

Figure No. 18: Arial view of the roadway section chosen for second and third pool

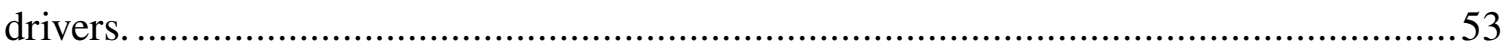


Figure No. 19 : Images showing the roadway conditions prevailing along the section

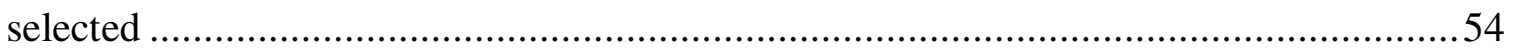

Figure No. 20: Images showing the roadway conditions prevailing along the section

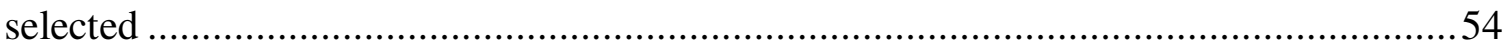




\section{LIST OF TABLES}

Table No. 1: Summary of results from t-test analysis ............................................ 30

Table No. 2: Total Distraction Durations by Driving Experience ..............................31

Table No. 3: Total Distraction Durations by Gender ...................................................33

Table No. 4: Percent Time Spent Looking at COR by Driving Experience....................35

Table No. 5: Percent Time Spent Looking at COR by Gender ..................................37

Table No. 6: Number of glances by Driving Experience ...........................................39

Table No. 7: Number of glances by Gender .................................................... 41 


\section{LIST OF APPENDICES}

A.1: Approved IRB Protocol.................................................66

A.2: Approval from the Board of Education...................................68

A.3: Approval from Morgantown High School.....................................69

A.4: Approval from University High School...................................70

A.5: Parental Consent form for high school students............................. 71

A.6: Assent form for high school students.................................... 75

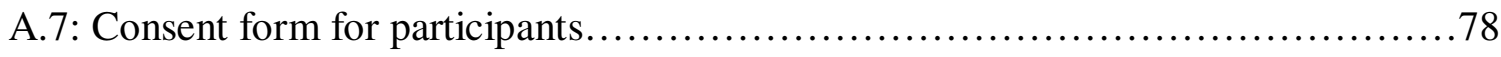




\section{INTRODUCTION}

\subsection{OVERVIEW}

Driver distraction is a major concern in highway safety. A driver is said to be distracted when he/she spends a longer time than required for the safe operation of the vehicle, at something that attracts his/her attention, thus leading to a deviation from the primary task of driving (1). It has been found that distraction is related to crashes. Back in the 1980's, National Highway Traffic Safety Administration (NHTSA) estimates that 25 to 30 percent of all crashes are due to the various kinds of driver distraction (2). An analysis of distraction can lead to a greater understanding of the variation in distraction exhibited by different drivers and to what extent distraction leads to crashes.

Driver distraction can be due either to on-road, in-vehicle or driver factors. Billboards and advertisements along the roadway and the traffic itself account for the bulk of the onroad distraction factors. Cellular telephone conversations and text messaging, Global Positioning System-aided map displays, stereo systems and conversations include the major in-vehicle distraction factors. A driver's physical and mental workload, fatigue, age and experience form some of the driver factors contributing to distraction. An increased level of distraction or inattention of driver leads to traffic crashes.

The behavior of a driver varies by age and health (26) (27) (28). The driving skills of older drivers decrease with an increase in perception-reaction time, a decrease in agility and a decrease in visibility. These factors affect the older driver's ability to avoid some crashes. Past research has found that age; and hence, experience is related to crash rates. 


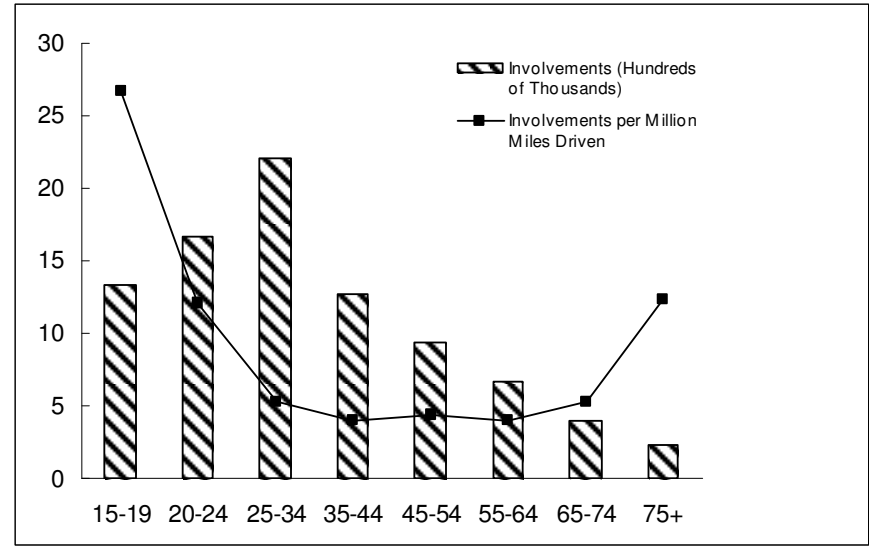

Figure 1: Variation of fatality rates with age group

(Source: Transportation Research Board, Transportation in an Aging Society: Improving Mobility and Safety for Older Persons, Special Report 218[1988].)

As shown in the Figure 1, fatality rates and age follow a U- shaped function, i.e., the fatality rates decrease as driver age increases. After a certain age, fatality rates start to increase again (3). Fatality rates are the highest for drivers between 15 to 19 years of age. The rates decrease with age and remain relatively constant for about until 64 years of age and then start increasing.

It is, perhaps, not clearly evident from past research whether the higher crash rate in young, novice drivers is due to inexperience or a higher distraction level. It has been stated that the crash rate varies depending on driver age and that distraction is the cause for many crashes. But, is distraction related to age? Are younger drivers easily distracted by roadway or in-vehicle factors? Is it possible there is difference by gender? It depends on how distraction is defined. Further research in this direction may lead to a greater understanding of the relation between driver distraction and age. As "driver experience is 
considered a derivative of age" and as experience increases with age (34), further analysis can also help understand the relation between driver distraction and experience.

"Looking in the wrong direction or taking your mind off driving at a critical moment can lead to a disastrous consequence while driving" (4). In 1977, "recognition errors" were reported to be the causes for 92.6 percent of crashes involving human factors (5). Most of the previous studies have concentrated on testing the inattention or distraction of drivers either on a test track or in a simulated environment. Though driving situations today are more complex given the presence of multiple in-vehicle technologies, advancements in driver assessment technology can help examine the distraction levels in an actual road environment. The causes of the distractions may also be determined.

Drivers should be attentive to react to any situation right away. Any delay in this reaction is said to be a consequence of looking away during a critical event (6). Visual disruptions like faster saccades (fast eye movements), blinks and occlusions (eye closures) can also impair the visual system's ability to respond in a timely manner (7). This emphasizes the need to focus on assessing the distraction induced by visual factors on drivers.

\subsection{PROBLEM STATEMENT}

It is possible that driver inattention, and more specifically distraction, varies with age and the experience level of the drivers. Recent research suggests that young and novice drivers exhibit more distraction when compared to experienced drivers, i.e. novice drivers 
cannot deal with complex situations in the presence of a secondary task due to their lack of experience (14). Research done by Lee, et al., on the other hand, suggests that novice drivers and experienced adult drivers made an almost equal number of glances under base driving conditions (8). Past research has also suggested that novice drivers tend to be more cautious while on the road compared to experienced drivers, i.e. they keep their eyes set at the center of the road for longer periods of time (probably assuming that looking straight at the roadway is the only need for careful driving) in less complex driving situations (8). A comparison of the inattention exhibited by novice drivers versus experienced drivers can help understand the level of distraction they undergo. Distraction can be caused due to several factors like roadside advertisements, surrounding traffic, traffic signs and conversations with other passengers in the vehicle.

Driver age and experience are related to each other, and there exists a variation in crash rate depending on both age and experience, but is there a relation between distraction and experience? Is it possible there is a difference by gender? It seems like this question has not yet been clearly addressed in past research. There is a chance that young and novice drivers are more easily distracted than experienced drivers.

Thus, the purpose of this study is to assess and compare the variation in distraction exhibited by drivers depending on experience. The study further analyzes the variation in distraction by gender. 
Several factors that may lead to distraction like global positioning systems (GPS) displays, cellular telephones and billboards have been emphasized in the past but not many studies have been done on verbal/oral distraction. An interactive conversation could make a driver inattentive. A study that considers conversations in the car as a factor contributing to distraction, along with advertisements and traffic that are common to all drivers, would provide a better understanding of how distraction varies with age and experience.

The major tasks of this study are to:

1. Determine how driver visual distraction can be defined and measured

2. Develop a method to track the distraction based on the definition given

3. Design an experiment to track and assess the variation in distraction by the use of appropriate equipment and software

4. Recruit participants as required, based on age and experience

5. Conduct the experiment as designed

6. Analyze the data collected and draw inferences from the results obtained

Performing the tasks listed above may lead to a greater understanding of the extent of distraction and how much it varies with driver experience. Assessing the distraction levels can help develop ways to improve driving skills. Extension of the study may also lead to the development of ways to mitigate the number of crashes due to driver distraction caused by in-vehicle factors. 


\section{LITERATURE REVIEW}

Driving is a complex task that demands carrying out various functions safely at a time. The most important of the tasks is vehicle control, which involves maintaining the right speed, headway and lane position while looking at the traffic around to maintain a safe gap in the traffic stream (9). "Driver errors occur when attention is focused away from a critical roadway event in which vehicles, traffic signals and signs are seen but not acted upon or are missed altogether" (30). Past research suggests that improper attention by drivers is a dominant factor in traffic crashes (10).

Research done by National Highway Traffic Safety Administration (NHTSA) suggested that driver distraction and traffic crashes are related (2). The extent of driver involvement in crashes decreases with experience as experienced drivers exhibit better road scanning patterns (8). Research has shown that young drivers tend to speed in traffic, pull into smaller gaps and glance away from the road (3) (24) (25) while experienced drivers increase their situation awareness and scanning pattern when on the road (8). A study on the variation of driver distraction with experience can help in understanding the relation between the two. This can further help in developing measures to be taken in order to reduce the number of traffic crashes due to distraction.

This literature review considers examining the relation between driver experience and extent of distraction and helps developing a method to test the relation between the two. This review begins with the definition of driver distraction followed by the classification 
of distraction. It later explains the various factors that can cause distraction depending on its relation with the road user. It further provides an analysis of various methods and technologies that have been adapted in the past to track the extent of distraction. The review continues with explanation of the variation of distraction with driver experience.

\subsection{Driver Distraction}

Driver distraction has been defined as a deviation from the primary task of driving (1) (34). Driver distraction has also been defined as looking away from the roadway for more than 2 seconds (32) (33). According to Trent et al., glance duration of greater than 2 seconds indicates a task difficulty i.e., the secondary task is negatively influencing the primary task of driving (4). The task of driving can be categorized into control, guidance and navigation. Table No. 1 describes the various operations that a driver has to carry on while on the road. Any distraction caused to a driver at the control level can lead to a crash. Hence driver distraction has been a major concern to researchers. 


\begin{tabular}{|l|l|l|l|l|}
\hline $\begin{array}{l}\text { Subtask } \\
\text { Category }\end{array}$ & Related to & $\begin{array}{l}\text { Example of Sources } \\
\text { of Information }\end{array}$ & $\begin{array}{l}\text { Importance } \\
\text { of } \\
\text { Information }\end{array}$ & $\begin{array}{l}\text { Likely } \\
\text { Consequence of } \\
\text { Failure }\end{array}$ \\
\hline Gontrol & $\begin{array}{l}\text { Physical operation } \\
\text { of vehicle } \\
\text { Speed control } \\
\text { Steering control }\end{array}$ & $\begin{array}{l}\text { Road edges } \\
\text { Lane divisions } \\
\text { Warning signs } \\
\text { Kinesthesia }\end{array}$ & $\begin{array}{l}\text { Emergency } \\
\text { situation or crash }\end{array}$ \\
\hline Navigation & $\begin{array}{l}\text { Selecting and } \\
\text { maintaining a safe } \\
\text { speed and path }\end{array}$ & $\begin{array}{l}\text { Road geometry } \\
\text { Obstacles } \\
\text { Traffic conditions } \\
\text { Weather conditions }\end{array}$ & Intermediate & $\begin{array}{l}\text { Emergency } \\
\text { situation or crash }\end{array}$ \\
\hline Trip planning & $\begin{array}{l}\text { Experience } \\
\text { Directional signs } \\
\text { Maps } \\
\text { Touring service }\end{array}$ & Lowest & $\begin{array}{l}\text { Delay, confusion } \\
\text { or inefficiencies }\end{array}$ \\
\hline
\end{tabular}

Figure No. 2: Frame work of the concepts in Driving Task (Source: Paul H. Wright, Highway Engineering, $6^{\text {th }}$ edition)

Driver's mental awareness can be classified into distraction and inattention. Driver distraction can also be due to inattention which is called attention distraction. Distraction is always due to certain external or driver factors but inattention can be stated as the lack of mental concentration of the driver. The attention distraction can lead to a serious crash even if the driver does not shift the attention from on-road traffic (10).

Uno classifies driver attention status into five categories as:

1. Attentive

2. Distracted

3. Looked but didn't see

4. Sleepy or fell asleep

5. Unknown or no driver

Being attentive is a state in which the driver is in a condition to respond timely to a situation. The distracted condition is one in which the driver is looking else where. 
Another status of attention is when the driver looked at the event but was not mentally present to respond to that situation.

Uno also classifies driver distraction status into 13 categories based on the factor causing distraction as:

1. Eating or drinking

2. Outside person, object or event

3. Adjusting radio, cassette, or CD

4. Other occupants in vehicle

5. Moving object in vehicle

6. Smoking related

7. Talking or listening on cellular phone

8. Dialing cellular phone

9. Using device/object brought into vehicle

10. Using device/controls integral to vehicle

11. Adjusting climate controls

12. Other distraction

13. Unknown distraction

Most of the studies have focused on using device/object brought into the vehicle and also on using device/object integral to the vehicle. Distractions related to cell phone use have been the major concern in most of the recent studies. Various technologies have been adapted in the past to track the distraction caused by several factors like bill boards, advertising signs and several in-vehicle devices. Not much emphasis has been laid on 
distraction caused due to conversations with other occupants in the vehicle. A study that considers the effects of conversing with other occupants in the vehicle, along with other on-road distraction factors usually present, can explain how far these factors contribute to distraction.

\subsection{Classification of Driver Distraction}

Distraction can be subjectively classified into visual and non-visual distractions (10). Non-visual distractions can be subdivided into auditory, verbal and cognitive distractions. Auditory distraction is one in which the driver gets distracted by listening to a conversation or surrounding noise. The contributing causes behind verbal distraction are talking with a passenger in the vehicle or on a cell phone. Cognitive distraction can be due to mental workload. Conversations in the vehicle can be considered as a factor contributing to auditory and visual distractions, and depending on the intensity of thought applied, to cognitive distraction. Visual distractions are due to the factors that demand the visual attention of drivers. Researchers have focused on visual and auditory distractions. Talking or text messaging on a cell phone requires looking at the device (visual distraction); depending on the type of conversation it can lead to cognitive distraction. Audio and verbal distractions can also be caused due to talking on a cell phone. Thus cell phones have been considered as major contributors both visual and non-visual distractions.

Researchers have focused on visual distraction as a major contributing cause for crashes (10). Conversations in the vehicle on the other hand can cause auditory, verbal and 
cognitive distraction to the driver. Past research has indicated that listening and responding to a message has reduced the ability to make safe cross-traffic turning decisions (9). This indicates that non-visual distractions need more consideration. Passengers were reported to be the source of distraction in $10.9 \%$ of distractions related crashes in the National Automotive Sample System-Crashworthiness Data System (NASS-CDS) database for 1995-1999 (11). Talking, arguing or conversing with the passenger are reported to be the reasons behind $33 \%$ of crashes involving distractions due to passengers (12).

According to Hatfield et al., distractions from a passenger can be minimal when compared to other in-vehicle distracting factors like cell phones. When driving situation demands, more attention can be given to the primary task by stopping the conversation with the passengers but this is not the case with cell phones due to social reasons (12). On the other hand, presence of a passenger in the vehicle would reduce the crash risk as the passenger could warn the driver of an approaching danger or crash risk. Research has also shown that experience improves this situation (12).

On the contrary, "the primarily visual nature of the driving task and previously published literature would suggest the auditory task would have less impact on the primary task" (13). An auditory task can thus be considered to be less distractive compared to a visual task. Thus, the relation between auditory-verbal task and distraction is not clearly evident from past research. A study on the conversations in the vehicle with a passenger can explain the extent of distraction posed by conversations. 


\subsection{Factors causing Distraction}

Numerous factors have been considered that lead to driver distraction. They can be classified as a) in-vehicle factors, b) on-road factors and c) driver factors. The use of cell phones, audio players, global positioning system (GPS), etc., form the in-vehicle factors while roadside advertisements, traffic, environment, etc. form the on-road factors. Driver factors that might cause distraction include driver alertness, fatigue, mental workload and physical and mental condition. The extent of visual distraction caused by each of these factors can be attributed to the visual demand each of them requires. Greater the visual demand, greater is the level of distraction. Some examples of factors that cause different types of distraction in each of these categories are:

a) Statistical analysis by Schlatter et al. concluded that the number of crashes increased by $50 \%$ in the test scenario where drivers carried cell phone conversations compared to the control scenario (2). Interactions with passengers in the vehicle can also be a source of distraction (11).

b) Billboards and roadside advertisements have been considered as factors contributing to driver distraction. In fact, it is a difficult task to establish a relationship between advertising billboards and safety due to several theoretical and methodological reasons like, not being able to determine the extent to which signs are guiding or distracting the drivers. In spite of the complexities involved, researchers have examined the effects of billboards on safety. The results are mixed and inconclusive (15).

c) The driving performance decreased with an increase in cognitive load, it deteriorated more in case of an increase in visual load (16). The drivers seem to 
look at the road when thinking about something but they are distracted, they are concentrating their attention on other matters. This is cognitive distraction.

\subsection{Measurement of Distraction}

\subsubsection{Technologies used}

The major distraction measuring methods that have been adopted in the past are 1) using peripheral detection task, 2) memory tasks, 3) by studying the eye movements of drivers and 4) other methods.

1) Peripheral detection task:

This method is sensitive and is used to measure short but high peaks in mental workload/distraction levels $(35,36)$. In this method, an object is presented to the driver that appears only for seconds and the driver needs to respond to it within seconds. Any delay in this reaction can be due to distraction or inattention of the driver. An analysis of the application of PDT to measure distraction suggested that it can only measure the variations in selective attention i.e., it can be effectively used to measure cognitive distraction $(35,36)$.

2) Memory Task:

Memory tasks include testing the driver's mental alertness. The drivers are presented with certain criteria as they drive and are asked to recollect the criteria or objects presented to them along the drive or after the drive $(46,47)$. 


\section{3) Eye Glance Measurements:}

Another method for testing distraction is by tracking the eye movement measures such as glance frequency and mean duration (ISO 15002-1/15002-2). Sodhi in his treatise on eye movement published in 2002 stated that "Eye movements recorded at high frequencies can give important clues to human behavior" (40). Eye glance measurement methods have become well standardized (41). Factors that are usually considered in eye movement measures are glance frequency (number of glances at a particular target), glance duration and percent of time (8). An analysis of the frequency and duration of eye movements can give the amount of attention each factor demands. Eye movements can be measured using eye tracking devices. In the research done by Sodhi et al., eye movements were tracked using a head mounted tracking device and an analysis of the results yielded that the attention was distributed between the driving task and the secondary task introduced in the study (40).

\section{4) Other methods:}

Other methods that have been used in the measurement of distraction include studying the lane keeping tendency and attributing errors like going out of lane to distraction/ inattention (37) (38) and testing the attention levels by asking the drivers to perform certain set functions. Distraction has also been tested by the use of instrumented vehicles that permit quantitative measurements of driver performance such as speed, braking performance, acceleration and steering in the field (39). The effect of traffic situations and cell phone use on driving was studied by Liu et al. by recording driver's 
physiological responses while driving. Driver responses were recorded using a portable Cardiovis ECG system and further analysis was carried out the recorded heart rate was used to assess the driver's workload (48).

Past literature suggests that measurement of the eye movements could be a better way to track visual distraction. Secondary tasks always require certain attention for completion. All this attention cannot be regarded as distraction as they could be carried out without affecting the primary task. Eye movement measures can also help in determining the amount of attention that can be given to secondary tasks.

\subsubsection{Testing Scenarios}

Distraction tests have been carried out in simulators, on test tracks and in real road environment. The choice of simulator and on-road study has been contradictory (41). Some researchers, though using simulators, argue that naturalistic context could be a better way to test (42). The reactions of drivers might not be close to reality considering the fact that drivers know that they will not be harmed in a simulator.

On the other hand, other researchers argue that true testing conditions and criteria can be better provided in a simulated environment which can be later generalized to real world $(43,44)$. In case of a simulator, all the testing conditions can be completely provided and the researcher has complete control over the experiment. This way it is easier to apply the obtained results to real road conditions. 
However, a real road environment is preferred wherever possible i.e., when performing the experiment does not cause any harm to the driver, as the reactions of drivers can be much closer to reality when compared to simulated driving. When conducting a test on a real road scenario can be dangerous and a simulated environment is assumed to be not closer to reality, a test track would be preferred. This way the driver is not exposed to any danger from additional traffic as the vehicular traffic is controlled by the experimenter.

\subsection{Level of Experience and Distraction}

Drivers need to be cautious and react in a timely manner to a situation. Any kind of distraction or inattention delays this process. According to S. J. Kass et al.,(14) “As drivers move through the environment, they must identify the relevant information in rapidly changing traffic patterns (e.g., distance to other vehicles, closing speed) and be prepared to react to events that may occur in order to avoid accidents". Novice drivers due to the lack of experience might not be able to deal with complex road conditions when compared to experienced drivers (14). Given this inexperience, young drivers take risks and have higher chances of getting distracted when compared to experienced and older drivers, thus leading eventually to an increase in fatality rates (3).

On the other hand, experienced drivers make higher number of glances at the mirrors and also at the road environment compared to less experienced drivers (8). From the above discussion, past research on the number of glances made by novice and experienced 
drivers appear to be contradictory. A study on the glance patterns of experienced and young novice drivers can help understand the variation in distraction.

An analysis of how distraction varies with experience might be helpful in developing ways to reduce the number of crashes caused due to distraction that involve novice drivers. Research done by Wierwille and Tijerina (1996) indicated that a considerable number of crashes in North Carolina involved distraction due to a source inside the vehicle including objects, instruments (cell phone, radio) and interacting with another person or animal (45). Thus conversations inside a vehicle may be considered as a very important distracting factor.

Distraction can be due to several factors as mentioned earlier. This study focuses on distraction caused by standard conversations in a vehicle along with other distracting factors like road side advertisements and traffic. Standard conversation can be defined as a talk related to what the driver did on the day, climate, classes they are taking, general traffic in the city, etc. The conversations thus were limited to those that did not induce much mental workload on driver. 


\section{METHODOLOGY}

As driving is primarily a visual task, this study analyzes how driving is affected by common visual on-road factors (traffic, advertisements) and non-visual factors (invehicle conversations) by tracking the eye movements. This research thus focuses on the analysis of eye glance movements of drivers and compares the data among drivers of different experience levels. An eye tracking system can help study the eye glance behavior of the drivers. An analysis of the eye glance data can help understand the amount of attention contributed to the secondary task. This attention given to the secondary task can be defined as distraction if it exceeds the limits. If the driver is deviating from the primary task for less than two seconds, it is considered as inattention. If this inattention exceeds the two second limit, it can be called distraction. This two second limit has been used in past research and has been used considering the average perception reaction time required by the driver in order to avoid a crash. A comparison of the glance data between experienced and novice drivers can help understand how distraction levels change with age/experience as experience is considered a derivative of age. This might further help in developing some correction measures that can reduce distraction thereby reducing the number of crashes related to distraction.

Distraction in this study is defined as looking away from the center of roadway at something not relevant to driving for more than two seconds; this criterion has been used in past research (32) (33). The distraction duration was also considered for an period of 1.5 seconds but the results did not vary significantly and hence two second duration was 
used for further analysis. The main focus is on determining the distraction factors and comparing them among drivers of different experience levels and gender. The distraction factors considered in this study are:

1) Total distraction duration,

2) Number of glances at the center of roadway and

3) Percent time spent looking at the roadway.

Distraction duration can be defined as the time when the driver is looking away from the center of roadway (COR) for more than two seconds. Total distraction duration is the sum of the distraction durations for one driver.

\section{Equipment:}

As mentioned before, driving is primarily a visual task. There might be visual and nonvisual distractions associated with driving. In order to analyze the amount of visual distraction caused by secondary tasks, the use of equipment that tracks the eye movements is crucial to this research. Hence, an eye tracking system is required in this study. A faceLAB eye tracking system is used, which consists of a set of two cameras fixed on the dash board and a laptop that records and saves the data. The equipment tracks the eye movement and gaze of the driver as he drives and enables real-time analysis of eyelid movement, head pose and gaze direction. The equipment enables the tracking of each eye separately and takes into account the blinking and eye closure of the driver. The measurements are considered to be accurate as the tracking is based on eyelid position rather than bright pupil or corneal occlusion i.e., the measurements are based on the position of the eyelid rather than the brightness of the eye or percent of eye closure. The cameras adjust to the changes in driver's pose once calibrated (23). 
As the cameras are small and need not be in contact with the driver as compared to the head mounted system, they do not pose any additional distraction or inconvenience to the drivers. Driver's eye movements were recorded using this system. Some specifications of faceLAB:

- Automatic tracking initialization when face is only 20 percent of total image width;

- Tracking and recovery up to $+/-90^{\circ}$ around neck axis (turn head from shoulder to shoulder);

- $\quad$ Tracking and recovery up to $+/-45^{\circ}$ around nod axis (look up / look down);

- Tracking up to $+/-120^{\circ}$ and recovery up to $+/-30^{\circ}$ around tilt axis (lean left / right).

- $\quad$ Eye rotations of $+/-45^{\circ}$.

faceLAB is said to give accurate results when calibrated correctly. The following measures are taken in order to avoid any discrepancies.

- The eye tracking system is calibrated in relation to selected facial positions in order to avoid any errors in the final results.

- Drivers are asked not to wear sun glasses as this could give inaccurate results.

- Driver's eye movements might vary with familiarity. Hence a route that is familiar to all drivers is chosen.

Thus the system was set very carefully and the subjects were carefully selected taking into consideration care the above factors, in order to get accurate results. 
Drivers of different experience levels are considered in this study. Young and novice drivers, 16 to 18 years old, obtaining their training in driving from a driving school comprise the first group of subjects. Students from University High School and Morgantown High School in Morgantown, West Virginia were chosen. Drivers with less than a year of licensed driving experience, between the ages of 18 and 25, formed the second group of subjects. Experienced drivers (5 or more years of experience) between the ages of 30 to 50 comprised the third group of subjects. Drivers older than 50 years were excluded considering the probability of reduced perception reaction time in older drivers. A sample of 30 subjects in each group was considered to be sufficient as there might be some discrepancies in some cases and the data cannot be used in such cases. Eye movement data was actually collected from 31 participants in second and third groups. One participant data was eliminated from third group as the driver was over 50 years old and from the second group due to technical errors.

Terminology used for the groups:

- First Group: High school students

- Second Group: Drivers with less than one year of licensed experience

- Third Group: Drivers with more than five years of licensed experience

As required by the West Virginia University Institutional Review Board (WVU IRB) prior approvals from the Board of Education, parents of high school students, Principal and instructors of the high school drivers were obtained. The approval letters are shown 
in appendices 1through 4 . The drivers were given sufficient information about the project before they drove and their consent was obtained on signed forms. Consent forms are obtained from parents of drivers who are less than 18 years of age. The driver consent forms for high school students along with other drivers and the parental assent forms are shown in appendices 5 through 7 . The distraction exhibited by all of these subjects is analyzed to determine the relation between driver experience and distraction. Distraction is assessed based on the time spent looking at something that is not related to or required for driving.

The high school drivers were not allowed to use cell phones or stereo system while driving during the driver education class. But they were allowed to talk with other passengers in the car. To maintain similar conditions, drivers from the other two groups were also asked not to use their cell phones or stereo systems. The additional factor introduced in the vehicle apart from those present when the driver is alone was standard conversations with passengers. The conversations were not scientifically controlled i.e., the talk did not begin or end at any particular location and the driver had the option of replying based on his/her convenience in the traffic situation. The drivers were provided with sufficient information about the route before beginning the drive.

All the drivers were asked to drive a section of road and their eye movements were tracked as they drove using faceLAB eye tracking system. The instrument was calibrated and adjusted for each driver before use in order to track the eye lid movement accurately. For group 1, a member from the research team was present in the rear seat of the car 
along with the instructor in the front passenger seat. For groups 2 and 3, two members of the research team, one in the front passenger seat and the other in the rear seat were present. The drivers from the second and third groups drove the same route while the high school drivers took different routes. The instructors chose the route for high school students depending on the experience of the drivers. The routes and driving durations varied highly for almost each driver in the first group. Hence, data from the first group was considered only for an understanding of the driving behavior of novice drivers.

Drivers from the second and third groups drove along the same section of road that was familiar to everyone to maintain uniformity of results. They drove a three mile section of state route 705 which is a familiar urban roadway. An aerial image of the roadway section chosen is shown in Figure No. 18. They were asked to make one complete run of the roadway section selected i.e., they had to come back to the point from where they started.

The route chosen required making an un-signaled left turn into the parking lot of a store and then returning to the origin of the trip from there. The driver needs to be alert in this situation as they have to make a turn against on-coming traffic. The selected section is a four lane road with a left turn center lane throughout the section selected. The section has six traffic signals, several commercial advertising boards and multiple driveways. Images of the conditions prevailing along the roadway are shown in Figure No's 19 through 23. 
In order to avoid the variation in results due to the traffic conditions prevailing, the study was conducted only during off-peak hours. Off-peak hours are chosen to avoid heavy traffic which increases the average time the driver is on the road causing a deviation in our study. Off-peak hours are also chosen as additional traffic on the road could pose additional distraction to the drivers. Drives are asked not to wear sun glasses as faceLAB may not give accurate results when sun glasses are used.

The eye tracking system used recorded the eye movement of the driver along the route. Due to its smaller size (as shown in Figure No 24) and no direct contact with the driver, the set of cameras does not cause any additional distraction. However, a few drivers initially complained that they were concerned about the presence of the cameras before they actually drove. But, they later said that they were comfortable as they drove and got used to them. In order to get the drivers familiar with the vehicle, the drive actually started from a relatively big parking lot but the eye tracking was started when the drivers were on the road. Drivers were also told they can take an additional drive to get familiar with the vehicle if they feel the need at the beginning.

For the high school students from Morgantown High School and University High School, Dodge Stratus 2005 vehicles were used. The cars used for the second group were variable but were all mid size. A Subaru Impreza 2008 was used for the third group of drivers. No SUV type vehicle was used just to maintain uniformity 
A plane is created representing the center of roadway using the faceLAB software. Similar planes are created for rearview mirror and the side mirrors too. The eye tracking system works along with the faceLAB software and creates a video with digital data that enables us to know where the driver is looking at each $1 / 60^{\text {th }}$ of a second. A snap shot of how the software records the data is shown in Figure No 25. The WorldView software enables us to see and analyze the video at a later time. A snap shot of the visual data provided by the software is shown in Figure No 26. This data is later converted to text using the same software which provides data relevant to the driving task such as glance behavior, name of the object being looked, blink duration, gaze orientation, head orientation, co-ordinates of the eye gaze, and saccades along with several other variables. Only those relevant to this study are considered in order to reduce the size of the data.

The driver eye glance behavior and time spent at something irrelevant to the driving task will yield the extent of distraction exhibited by the in-vehicle and on-road factors like conversations with other drivers, road side advertisements, prevailing traffic conditions, etc. Sample sheets containing all the variables are shown in appendices 4 and 5. 


\section{ANALYSIS}

The visual data converted to text gives several variables such as the head orientation of the driver, the gaze direction, the object the driver is looking at as he drives, object towards which the head is oriented, blink frequency, experiment time, gaze quality, blink duration, pupil diameter and various other parameters. The parameters that are relevant in the determination of the various factors under consideration that enable understanding the extent of distraction are taken into account. Parameters such as number of glances away from the center of roadway, average duration of glances away from the center of roadway, time spent looking at the center of roadway are analyzed.

faceLAB gives the data in the form of variables relevant to each feature of the driver like eye, image features, head, timing and world. A few variables under each feature are as follows:

1. Eye: blink frequency, blink duration, pupil diameter, eye closure fraction and eye ball position.

2. Image features: eye pupil co-ordinates, mouth rectangle co-ordinates, face rectangle co-ordinates.

3. Head: head position, eye ball position, model quality.

4. Timing: experiment time, delay in seconds between image generation and logger data release.

5. World: name of the object in the world model towards which head and gaze are oriented, gaze direction. 
Variables for each eye are recorded individually in faceLAB.

The text format cells are imported into Microsoft Office Excel and all the files pertaining to each of the above mentioned variables are joined. Calculations to determine the percent time looking away from the center, number of glances at each object like center of roadway, left and right mirrors and rear view mirror are carried out. Total distraction time is calculated as the total time the driver is looking away from the roadway for more than 2 seconds and less than 5 seconds. This calculation was done using FORTRAN. The code used for this is given in Figure No 3. Given that a scene camera was not available, the traffic signal duration could not be determined while the drivers were on the road. Hence if the driver was looking away from the roadway for more than 10 seconds, that period of time was assumed to waiting at a traffic signal. A program was written using MATLAB and executed to determine the total traffic signal duration. This value and total blink duration were deducted from the total run rime and the obtained value was used in the determination of the variables under consideration. The MATLAB code used is given in Figure No 4.

A statistical analysis is carried out to using STATA to determine the extent of the variation in driver distraction with driver experience and gender. The variables included in the analysis are percentage of time spent at looking away from the center of roadway, number of glances at the center of roadway, number of glances at the rear view and total distraction duration. An interpretation of the results, which helps understand the variation 
in the levels of distraction between drivers of different experience levels, is provided in the following chapter.

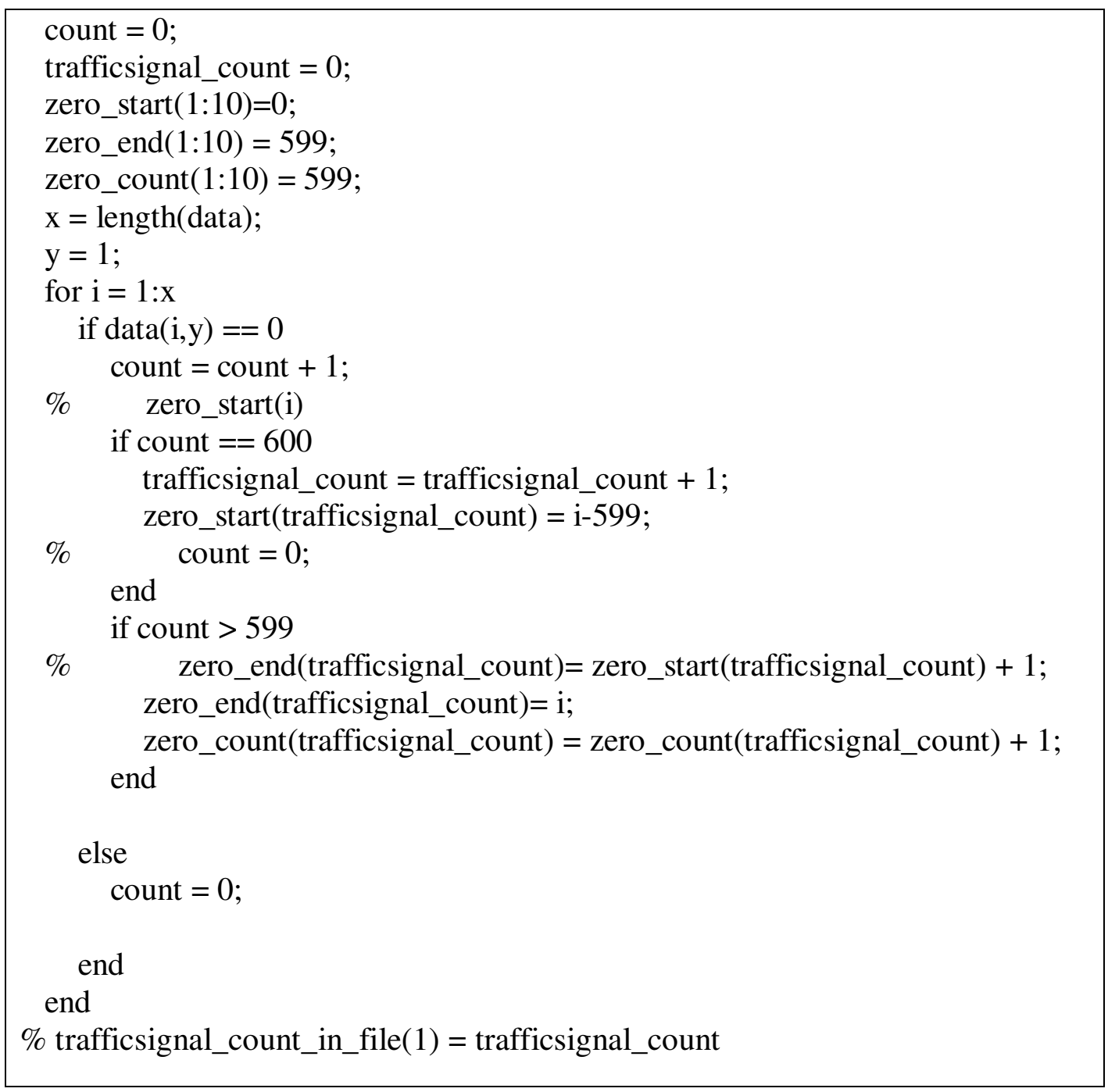

Figure No. 3: MATLAB code for Traffic Signal Count 


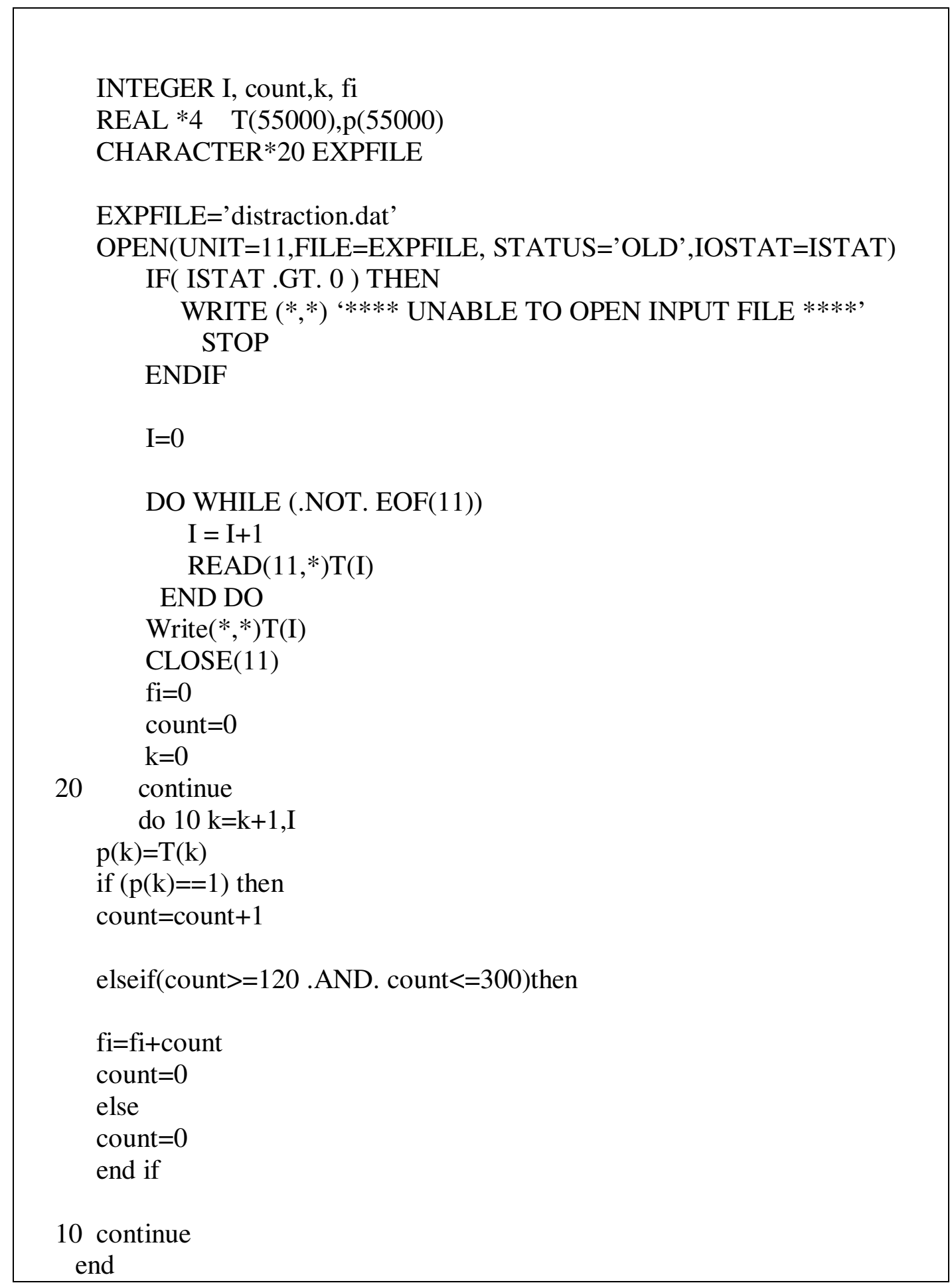

Figure No. 4: FORTRAN code for Total Distraction Duration 


\section{RESULTS}

This study focused on comparing the extent of distraction exhibited by drivers of different experience levels and gender. Participants in Groups 2 and 3 were considered in calculating the variation of distraction. This was due to the limitations in collecting the data for participants of Group 1. First, sample mean values for each variable were compared by experience and gender. Then, the statistical analysis was carried out at a 95\% confidence level. A difference is considered to be statistically significant if the pvalue calculated is less than 0.05 . Results from the analysis are summarized in the following table.

\begin{tabular}{|c|c|c|c|}
\hline $\begin{array}{c}\text { Eye measurement } \\
\text { factor }\end{array}$ & Comparison by & p-value & $\begin{array}{c}\text { Significant Statistical } \\
\text { Difference }\end{array}$ \\
\hline Total Distraction & $\begin{array}{l}\text { Driving experience } \\
\text { (Groups } 2 \text { and } 3 \text { ) }\end{array}$ & 0.7127 & No \\
\hline Duration (not looking) & Gender & 0.6686 & No \\
\hline Percent time spent & $\begin{array}{l}\text { Driving experience } \\
\text { (Groups } 2 \text { and } 3 \text { ) }\end{array}$ & 0.9098 & No \\
\hline looking at the COR & Gender & 0.8398 & No \\
\hline Number of glances & $\begin{array}{l}\text { Driving experience } \\
\text { (Groups } 2 \text { and } 3 \text { ) }\end{array}$ & 0.0077 & Yes \\
\hline away from the COR & Gender & 0.0270 & Yes \\
\hline
\end{tabular}

Table No. 1: Summary of results from t-test analysis 


\subsection{Total Distraction Duration by Driving Experience}

Sample Mean Values: As shown in Table No. 2, the mean value of total distraction duration was higher for drivers with less than one year of driving experience. Maximum and minimum values are also shown in the table. Figure No. 5 shows a higher mean value and maximum total distraction duration for novice drivers. These values suggest a tendency that experienced drivers might be less distracted under regular driving conditions.

Statistical Analysis: A t-test was carried out in order to determine if the difference in the distraction levels between the two groups was significant. However, the analysis did not yield a significant difference in the distraction (i.e., total glance duration at the COR for more than 2 seconds) exhibited by drivers with more than five years (Group 3) and drivers with less than one year experience (Group 2) at $95 \%$ confidence level. Results from the analysis are shown in Figure No. 6.

\begin{tabular}{|c|c|c|c|}
\hline Experience Level & $\begin{array}{c}\text { Mean Distraction } \\
\text { Duration (sec) }\end{array}$ & $\begin{array}{c}\text { Minimum Distraction } \\
\text { Duration (sec) }\end{array}$ & $\begin{array}{c}\text { Maximum Distraction } \\
\text { Duration (sec) }\end{array}$ \\
\hline $\begin{array}{c}\text { Drivers with less than } \\
\text { 1 year experience }\end{array}$ & 91.2 & 18.8 & 199.3 \\
\hline Experienced Drivers & 84.8 & 39.9 & 188.6 \\
\hline
\end{tabular}

Table No. 2: Total Distraction Durations by Driving Experience 

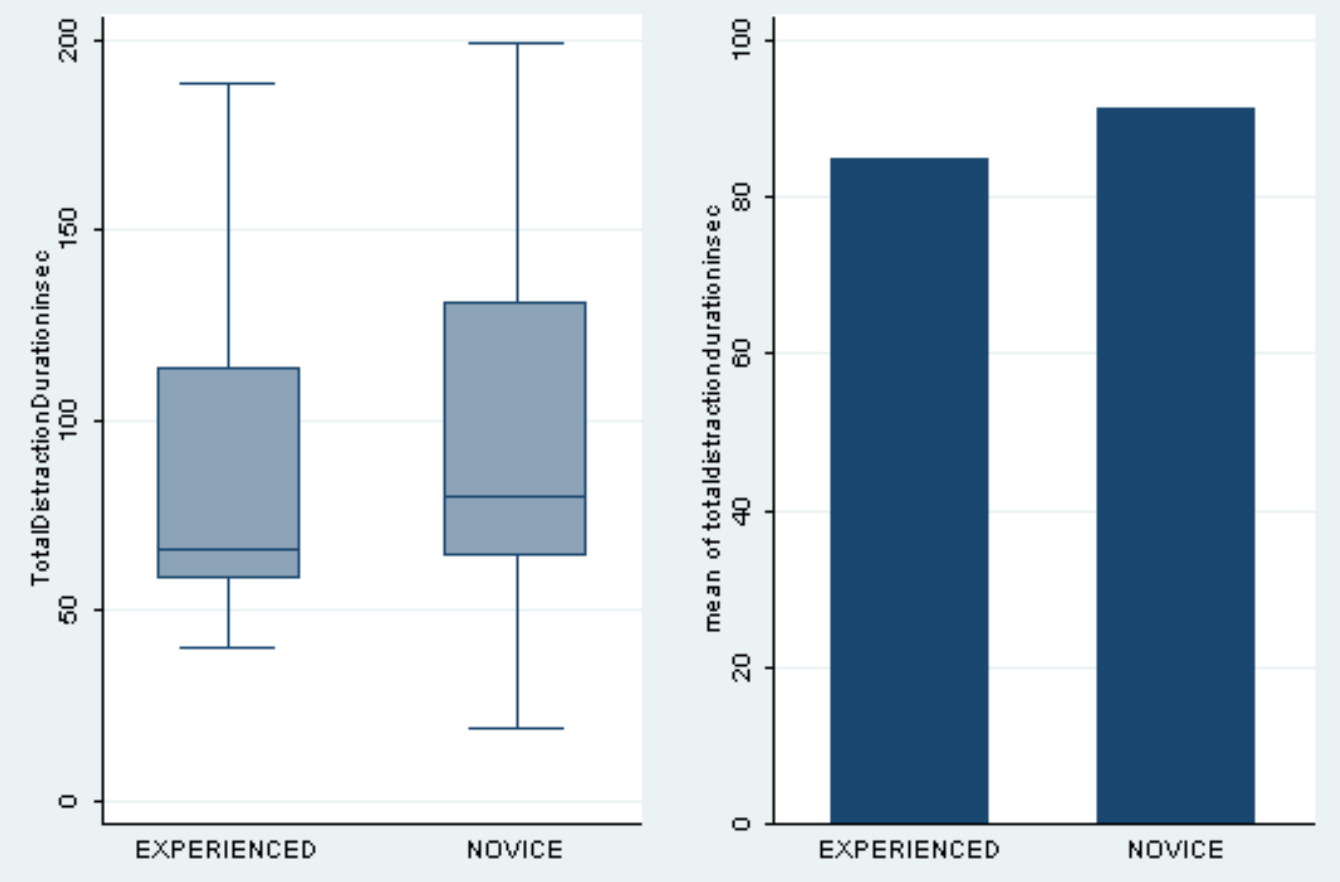

Figure No. 5: Comparison of Total Distraction Durations by Driving Experience

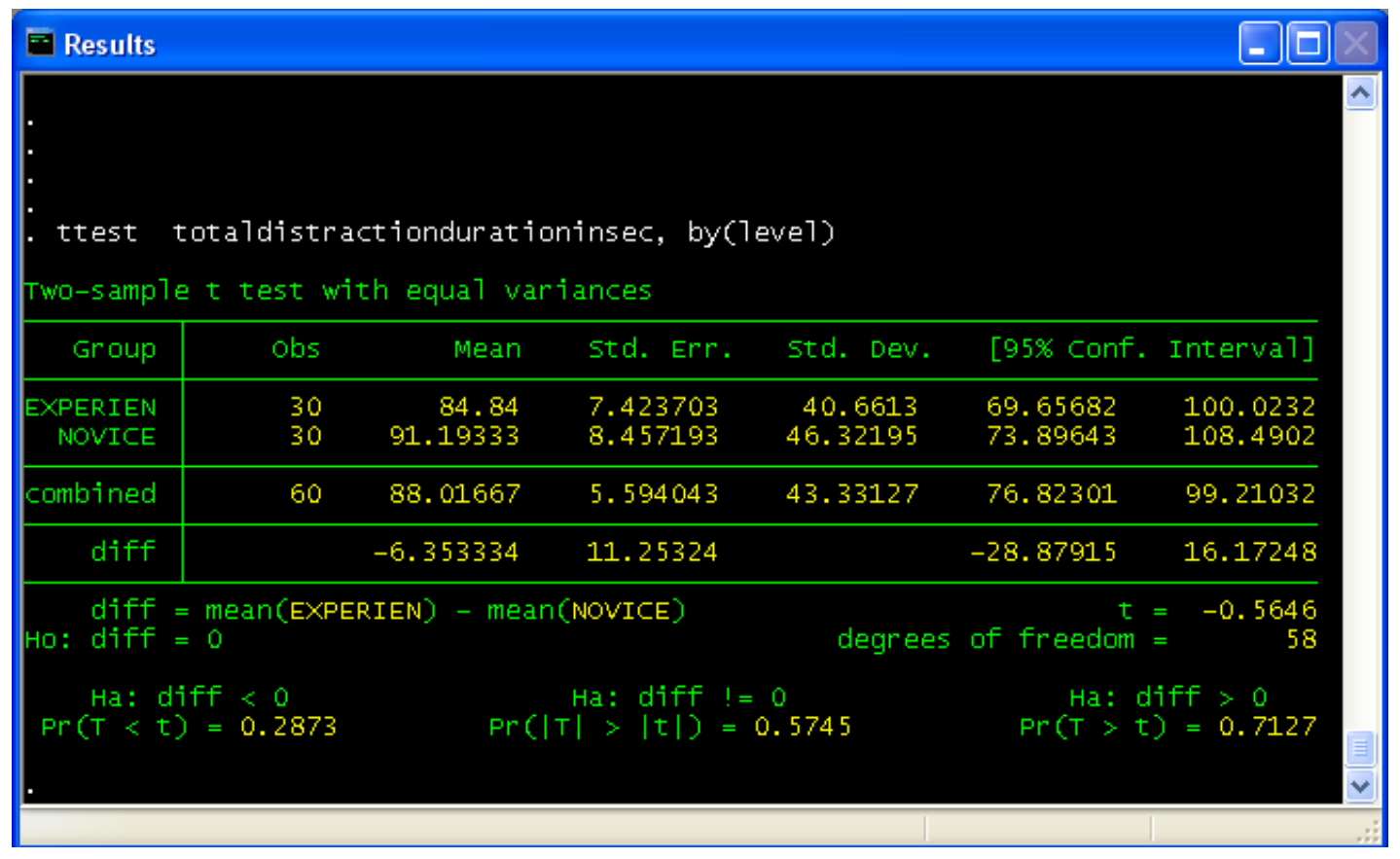

Figure No. 6: t-test results for Total Distraction Duration by Driving Experience 


\subsection{Total Distraction Duration by Gender}

Sample Mean Values: As shown in Table No. 3, the mean and maximum total distraction duration values were observed in male drivers. A comparison of the total distraction duration is shown in Figure No. 7. Maximum value of total distraction duration was observed for male novice drivers, the duration being a total of 199.3 seconds. The mean total distraction duration values, as shown in Figure No. 7 suggest that the distraction duration may be higher for male drivers.

Statistical Analysis: A statistical t-test was carried at 95\% confidence level to test the variation in total distraction duration by gender. Results from the statistical analysis are shown in Figure No. 8. No significant difference was observed in the total distraction duration of female and male drivers.

\begin{tabular}{|l|l|l|l|}
\hline \multicolumn{1}{|c|}{ Gender } & \multicolumn{1}{|c|}{$\begin{array}{c}\text { Mean Distraction } \\
\text { Duration (s) }\end{array}$} & $\begin{array}{c}\text { Minimum } \\
\text { Distraction Duration } \\
(\mathrm{s})\end{array}$ & $\begin{array}{c}\text { Maximum } \\
\text { Distraction Duration } \\
(\mathrm{s})\end{array}$ \\
\hline Female & 83.7 & 26.9 & 150.9 \\
\hline Male & 89.4 & 18.8 & 199.3 \\
\hline
\end{tabular}

Table No. 3: Total Distraction Durations by Gender 

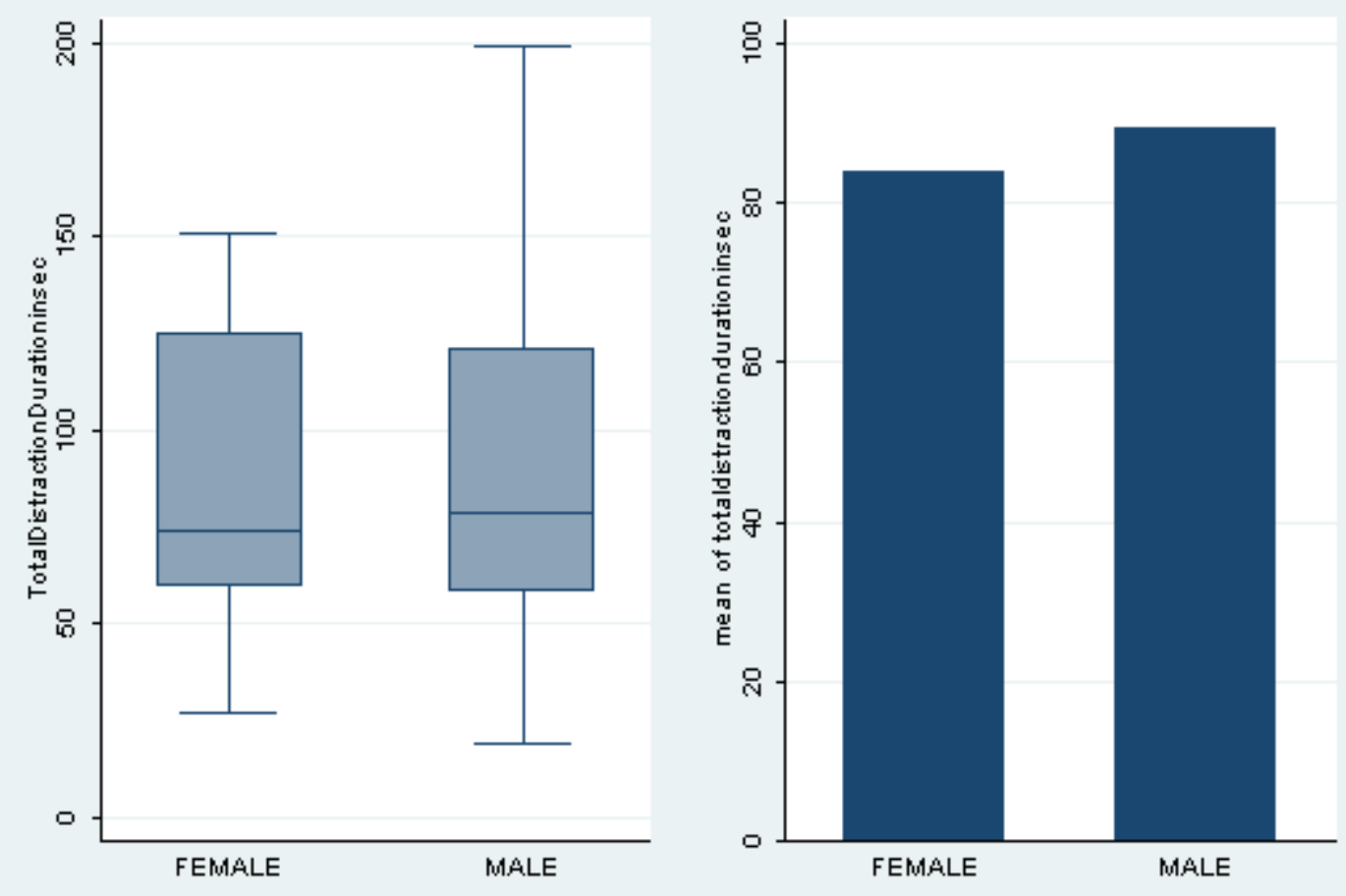

Figure No. 7: Comparison of Total Distraction Duration by Gender

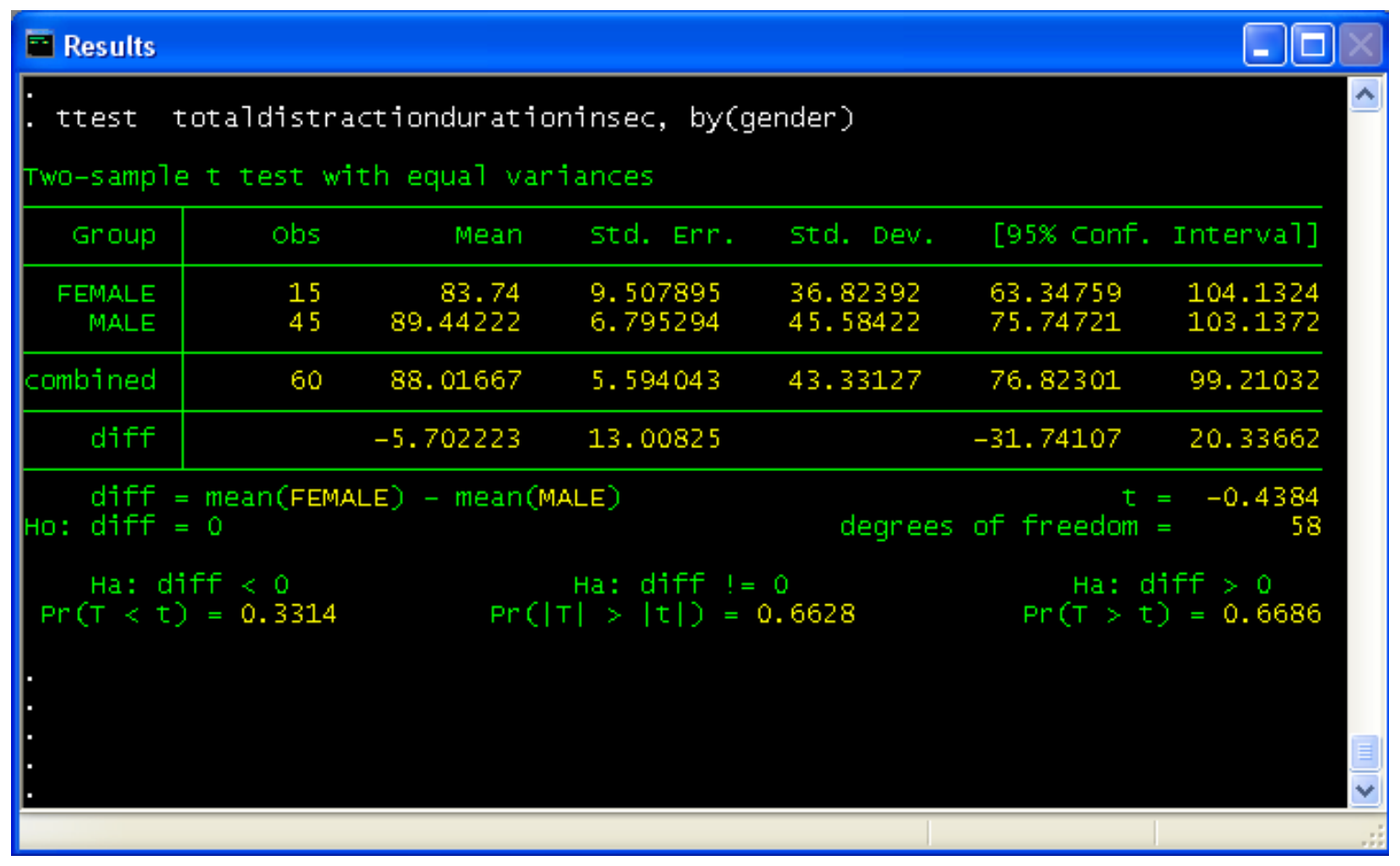

Figure No. 8: t-test results for Total Distraction Duration by Gender 


\subsection{Percent Time Spent Looking at COR by Driving Experience}

Sample Mean Values: As shown in Table No. 4, the minimum and maximum percent time spent looking at the COR were observed for drivers with less than one year experience (Group 2). A comparison of the percent time spent looking at COR is given in Figure No. 9. There was not much difference in the average percent time spent for both groups. The higher percent suggests that less experienced drivers spend more time looking at the COR while experienced drivers scan the environment more i.e., look at the mirrors along with looking at the center. As a mean value of $54.7 \%$ is not high, it can be said that though the novice drivers look at the COR for a longer time compared to other drivers, they might still be distracted.

Statistical Analysis: Statistical analysis of the percent time spent looking at the COR by experience was carried to test if the variation was significant. However, the t-test analysis did not give any significant results at the $95 \%$ confidence level as shown in Figure No. 10.

\begin{tabular}{|c|l|l|l|}
\hline Experience Level & $\begin{array}{c}\text { Mean \% Time Spent } \\
\text { at center }\end{array}$ & $\begin{array}{c}\text { Minimum \% Time } \\
\text { Spent at center }\end{array}$ & $\begin{array}{c}\text { Maximum \% Time } \\
\text { Spent at center }\end{array}$ \\
\hline $\begin{array}{c}\text { Drivers with less } \\
\text { than 1 year } \\
\text { experience }\end{array}$ & 54.68 & 10.28 & 90.6 \\
\hline Experienced Drivers & 49.18 & 24.58 & 74.35 \\
\hline
\end{tabular}

Table No. 4: Percent Time Spent Looking at COR by Driving Experience 

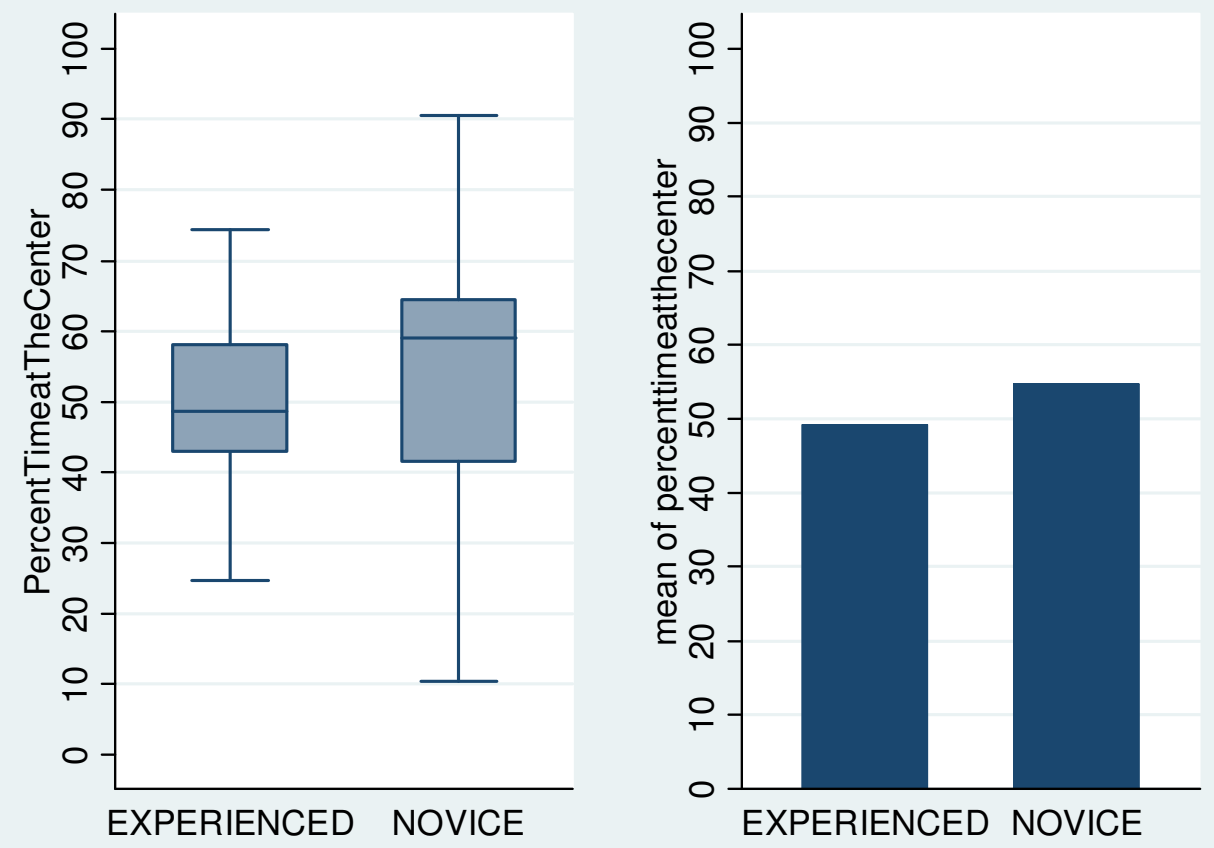

Figure No. 9: Comparison of Percent Time Spent Looking at COR by Driving Experience

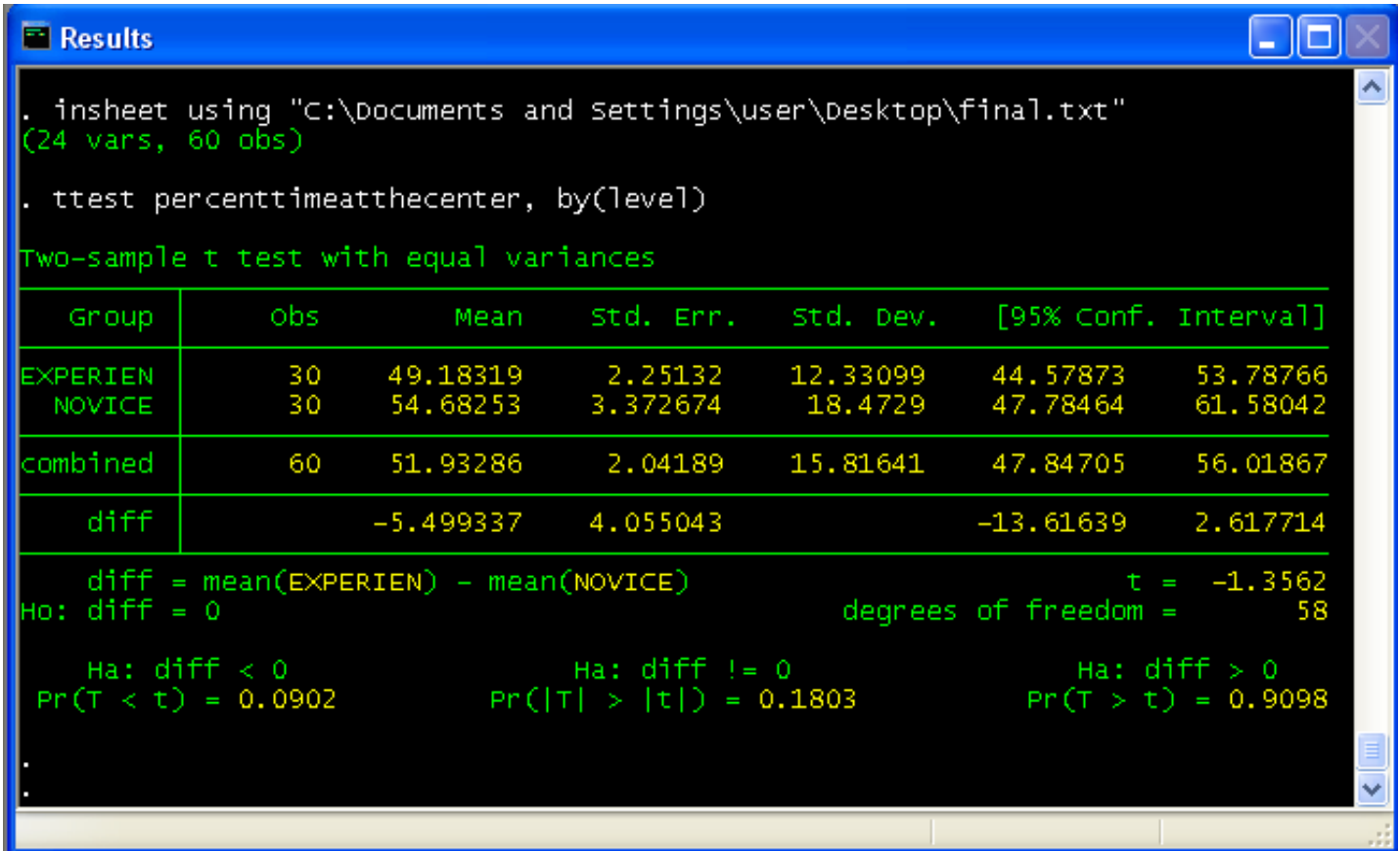

Figure No. 10: t-test results for Percent Time Spent Looking at COR by Driving Experience 


\subsection{Percent Time Spent Looking at the COR by Gender}

Sample Mean Values: The average percent time spent looking at the center was higher for female drivers compared to male drivers as shown in Table No 5. The minimum and the maximum percent time spent looking at the COR was observed for female drivers. This implies that the data for female drivers is highly variable. A comparison of the percent time looking at COR by gender is shown in Figure No. 11.

Statistical Analysis: A statistical $t$-test was carried in order to test for the significance.

The analysis did not yield any significant difference between the percent times as shown in Figure No. 12.

\begin{tabular}{|l|l|l|l|}
\hline Gender & $\begin{array}{c}\text { Mean \% Time Spent } \\
\text { at COR }\end{array}$ & $\begin{array}{c}\text { Minimum \% Time } \\
\text { Spent at COR }\end{array}$ & $\begin{array}{l}\text { Maximum \% Time } \\
\text { Spent at COR }\end{array}$ \\
\hline Female & 53.05 & 10.28 & 90.6 \\
\hline Male & 48.54 & 25.73 & 71.05 \\
\hline
\end{tabular}

Table No. 5: Percent Time Spent Looking at COR by Gender 

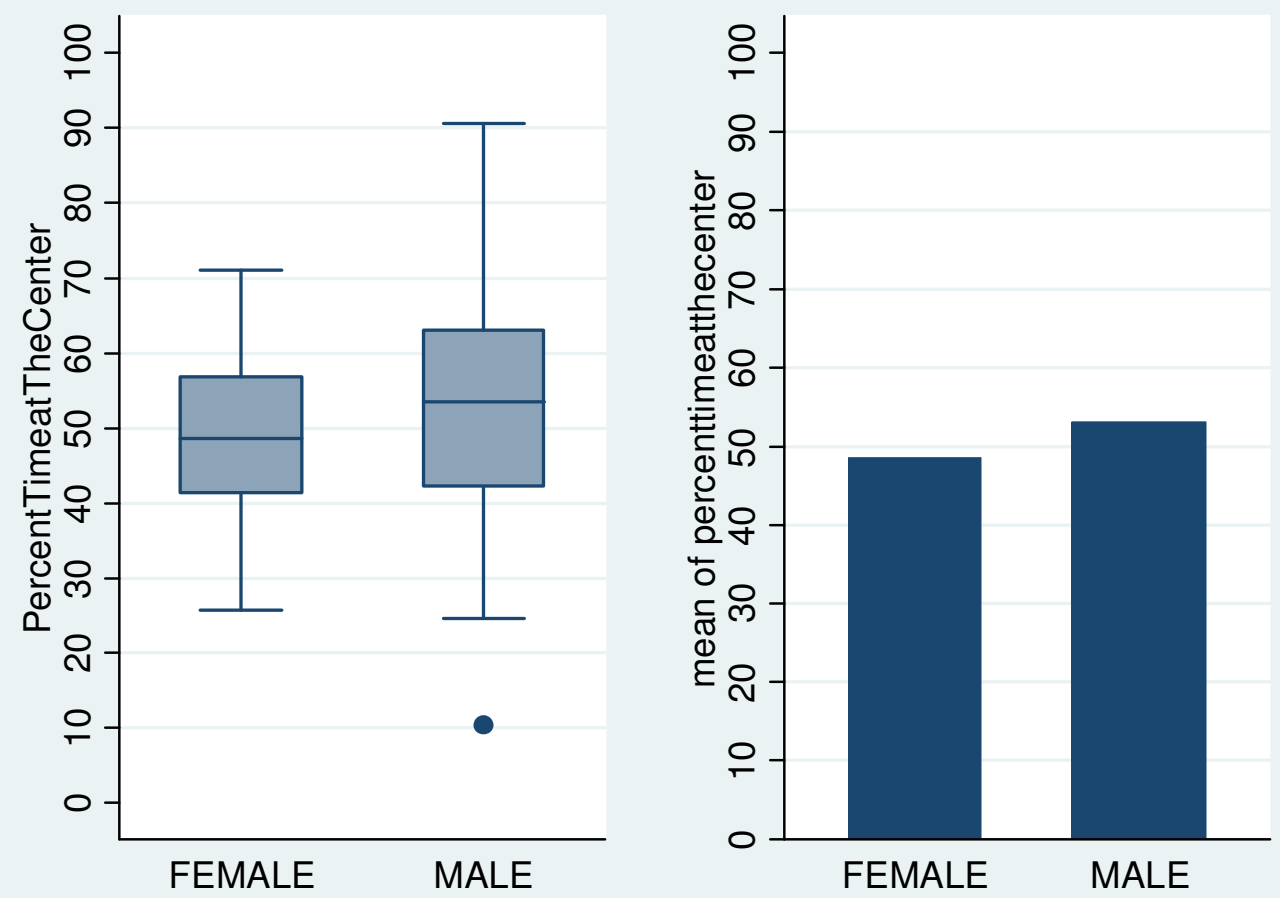

Figure No. 11: Comparison of Percent Time Spent Looking at COR by Gender

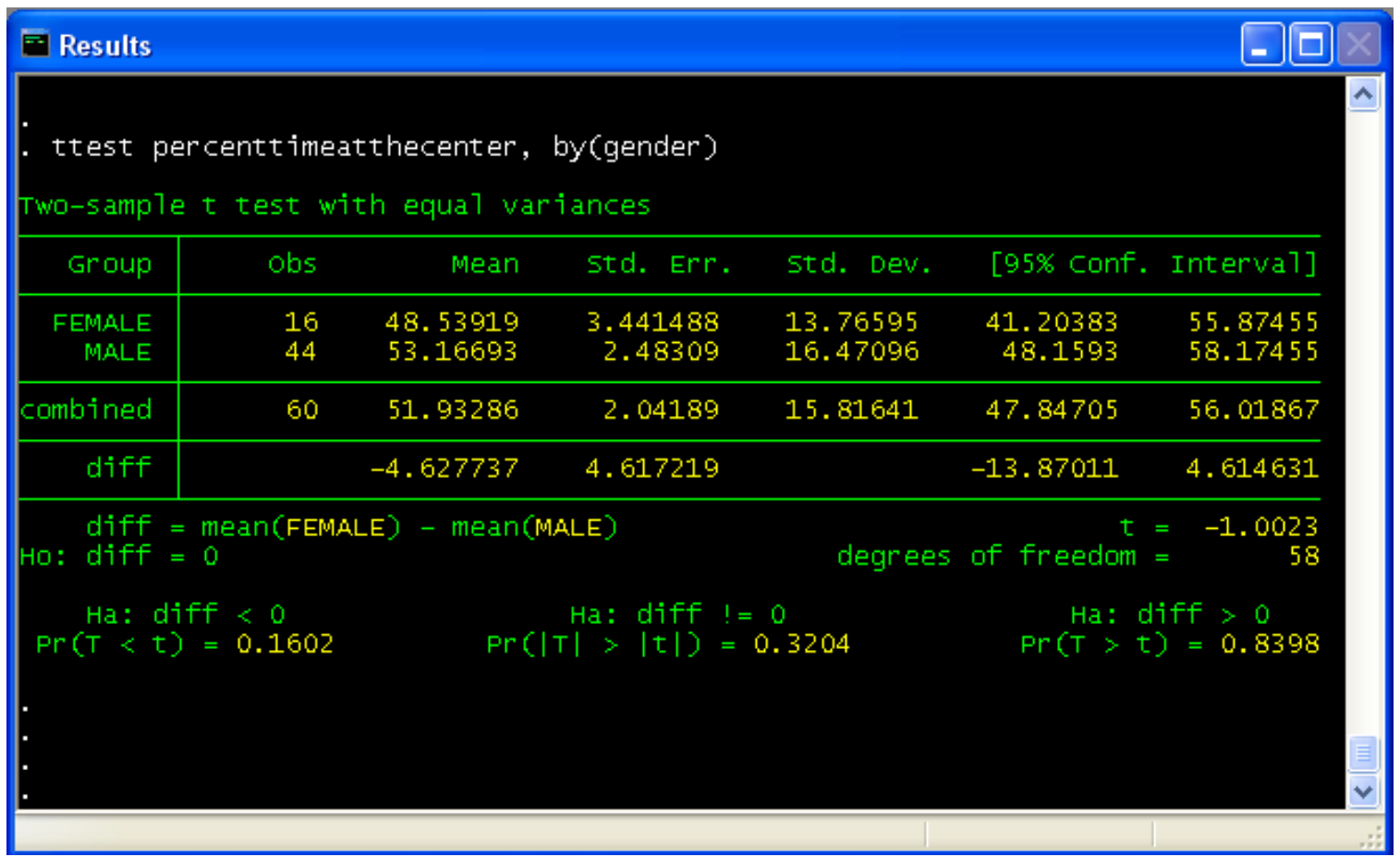

Figure No. 12: t-test results for Percent Time Spent Looking at COR by Gender 


\subsection{Number of Glances away from COR by Driving Experience}

Sample Mean Values: The number of glances at the COR was higher for experienced drivers (Group 3) compared to less experience ones (Group 2). The average number of glances at the center of roadway for both groups is given in Table No. 6. A comparison of the glances between experienced and less experienced groups is given in Figure No. 13.

Statistical Analysis: Results of the statistical analysis are shown in Figure No. 14.The $t$ test analysis yielded a significant value of 0.0077 , explaining that experienced drivers look away from the COR more than novice drivers. This shows evidence that experienced drivers scan the road environment more than less experienced ones.

\begin{tabular}{|c|l|l|l|}
\hline Experience Level & \multicolumn{1}{|c|}{$\begin{array}{c}\text { Mean Number of } \\
\text { Glances }\end{array}$} & $\begin{array}{c}\text { Minimum Number } \\
\text { of Glances }\end{array}$ & $\begin{array}{c}\text { Maximum Number } \\
\text { of Glances }\end{array}$ \\
\hline $\begin{array}{c}\text { Drivers with less } \\
\text { than 1 year } \\
\text { experience }\end{array}$ & 554 & 244 & 925 \\
\hline Experienced Drivers & 725 & 265 & 1461 \\
\hline
\end{tabular}

Table No. 6: Number of glances by Driving Experience 

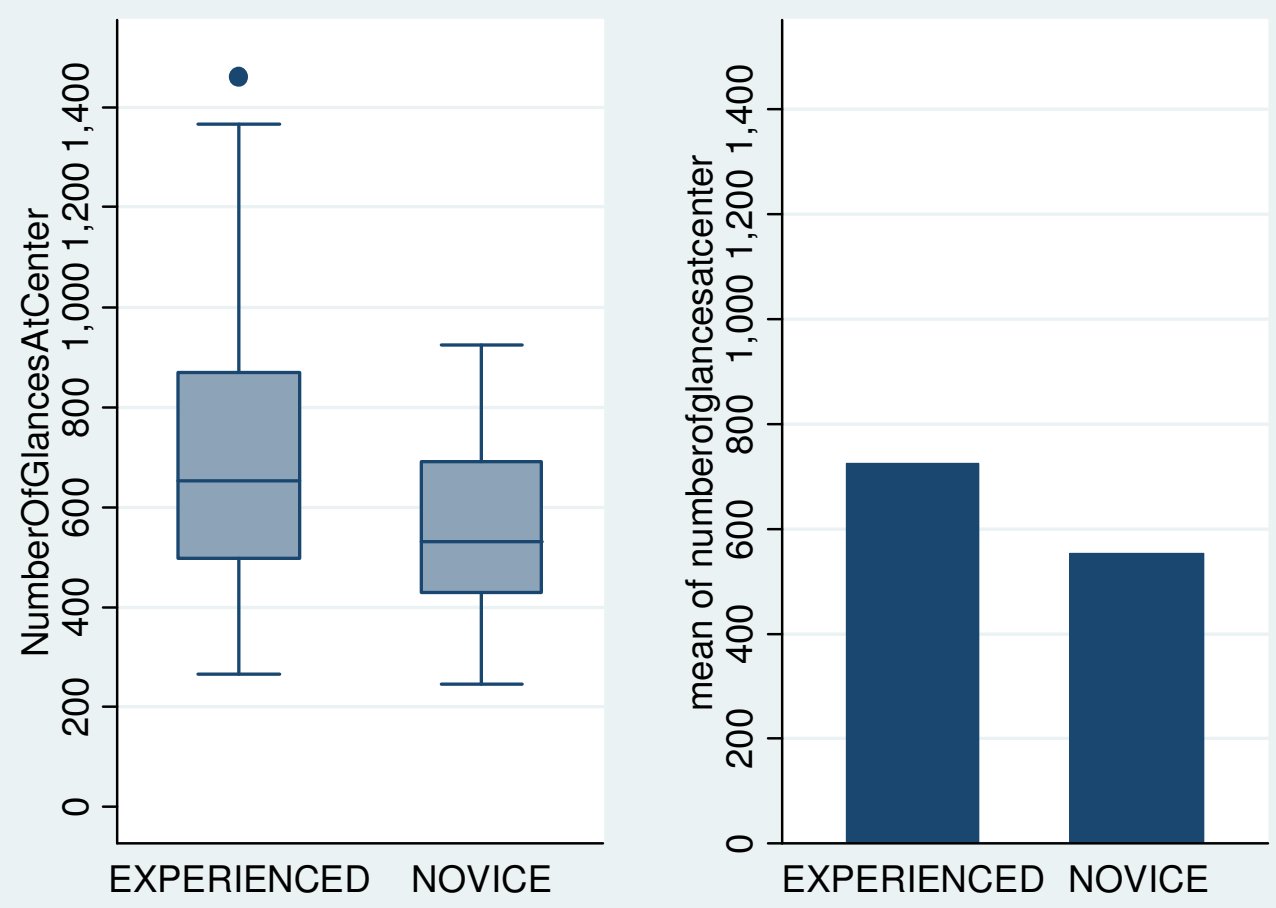

Figure No. 13: Comparison of the Number of Glances by Driving Experience

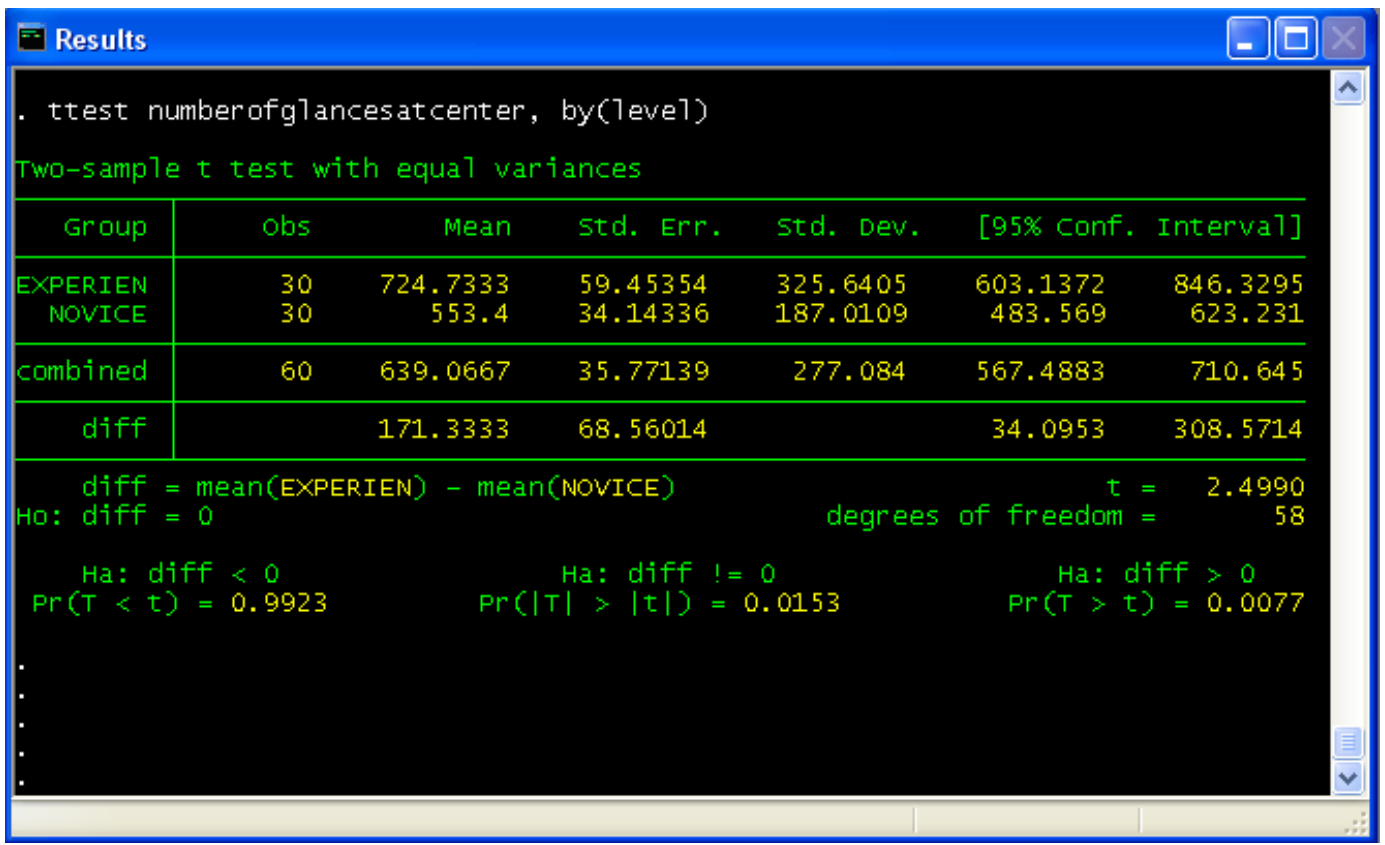

Figure No. 14: t-test results for Number of Glances by Driving Experience 


\subsection{Number of Glances away from the COR by Gender}

\section{Sample Mean Values:}

The average number of glances between female and male drivers suggests a difference as shown in Table No. 7. The mean number of glances was higher for experienced female drivers compared to female drivers with less experience. A comparison of the number of glances made is shown in Figure No. 15.

\section{Statistical Analysis:}

Upon analysis, it was found that the number of glances at the roadway was higher for female drivers at $95 \%$ confidence level. The statistical $t$-test yielded a significant value of 0.0270. Results of the statistical analysis are shown in Figure No. 16. Thus it is evident that female drivers make more glances at the COR compared to male drivers.

\begin{tabular}{|l|l|l|l|}
\hline Gender & \multicolumn{1}{|c|}{$\begin{array}{c}\text { Mean Number of } \\
\text { Glances }\end{array}$} & $\begin{array}{c}\text { Minimum Number } \\
\text { of Glances }\end{array}$ & $\begin{array}{c}\text { Maximum Number } \\
\text { of Glances }\end{array}$ \\
\hline Female & 753 & 333 & 1461 \\
\hline Male & 590 & 244 & 1366 \\
\hline
\end{tabular}

Table No. 7: Number of glances by Gender 

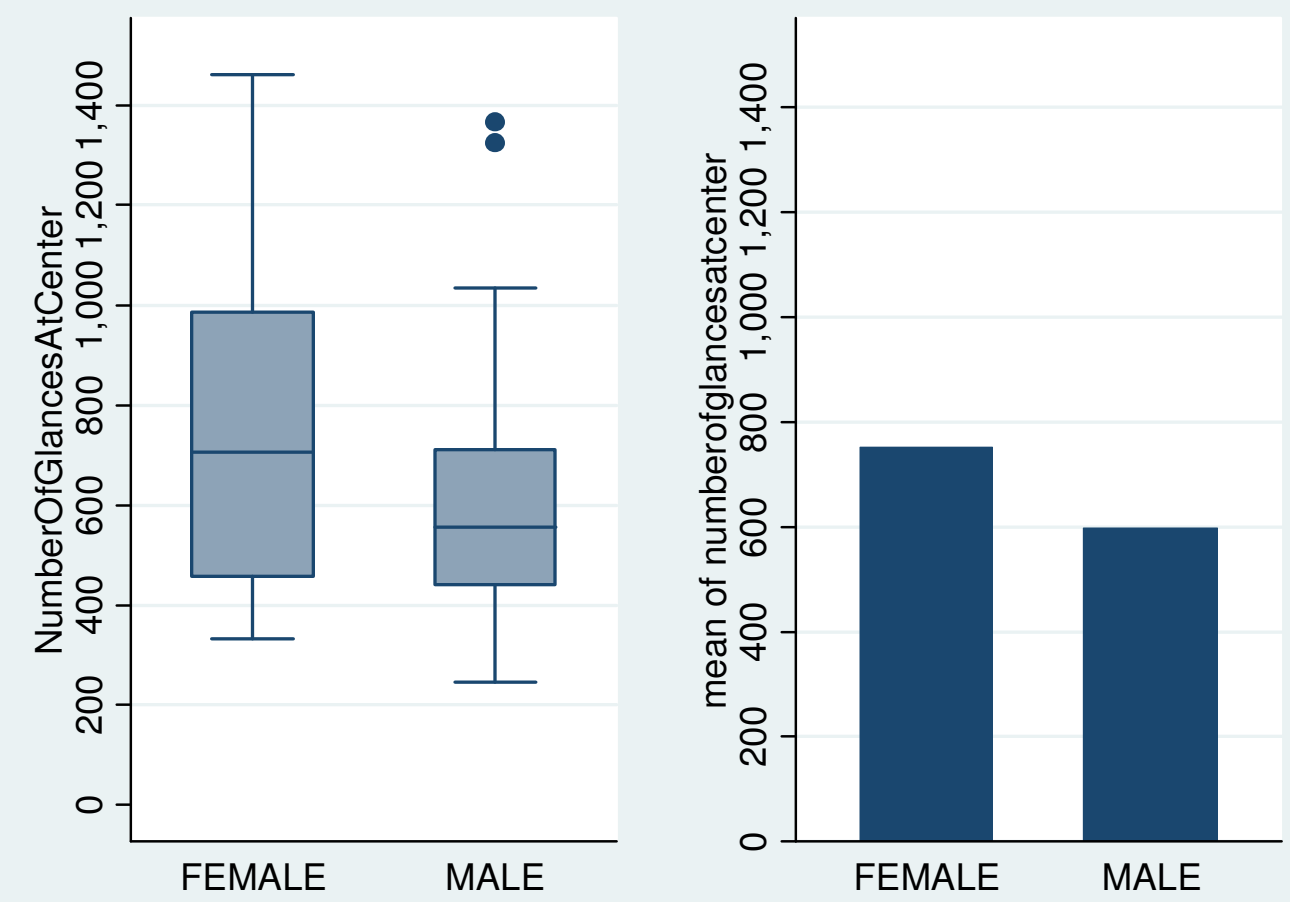

Figure No. 15: Comparison of Number of Glances by Gender

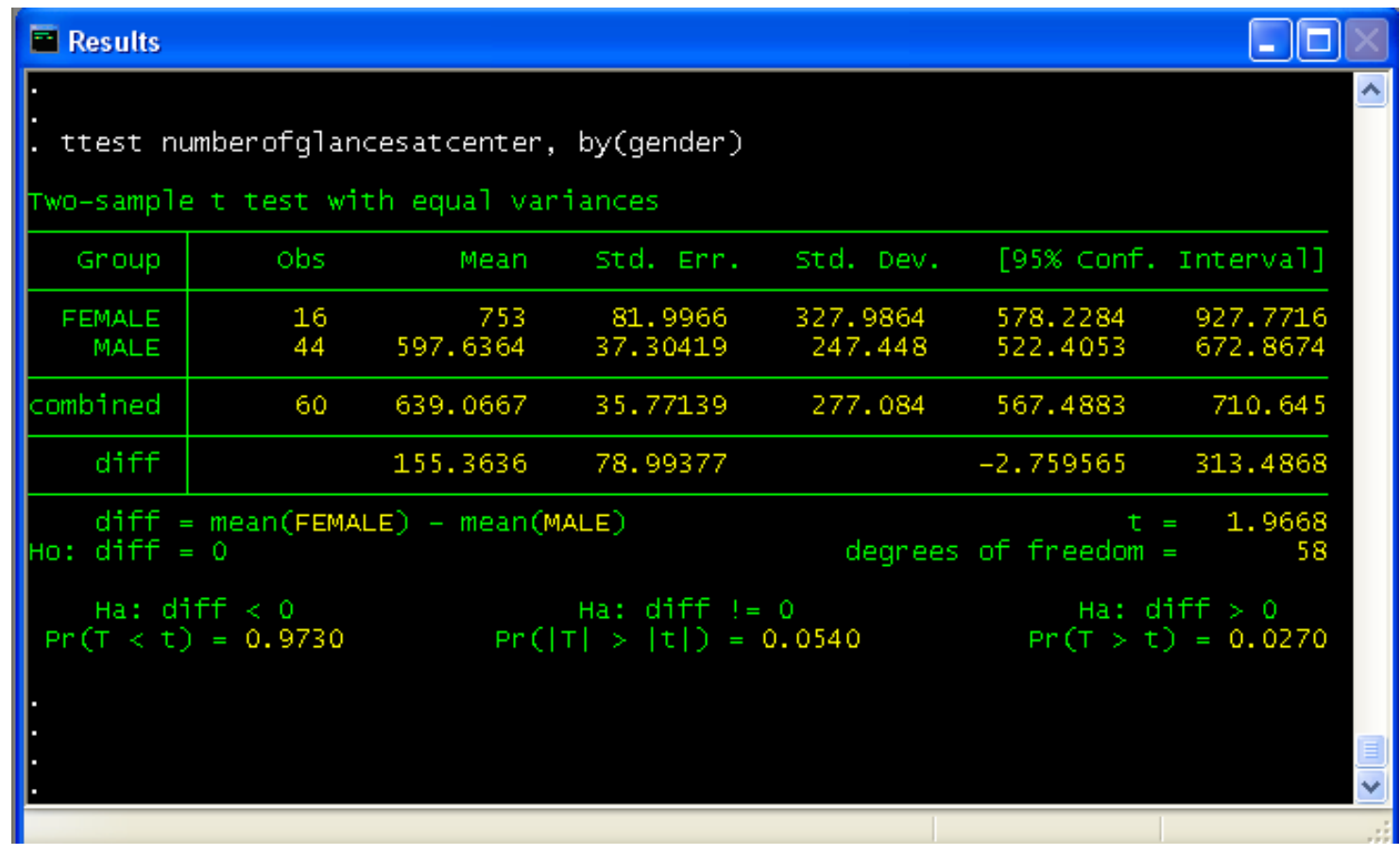

Figure No. 16: t-test results for Number of Glances by Gender 


\subsection{Percent Time Spent Looking at COR by Driving Experience (Groups 1, 2 and 3)}

Due to the limitations while recording the data for high school students as discussed earlier, the other variables such as number of glances at the center and total distraction duration is not considered in the analysis. The different routes and different trip durations taken by participants of group 1 did not provide for uniformity in the collection of data. A comparison of the percent time spent looking at the center is considered as it is based on the $\%$ time with respect to the total driving time per driver.

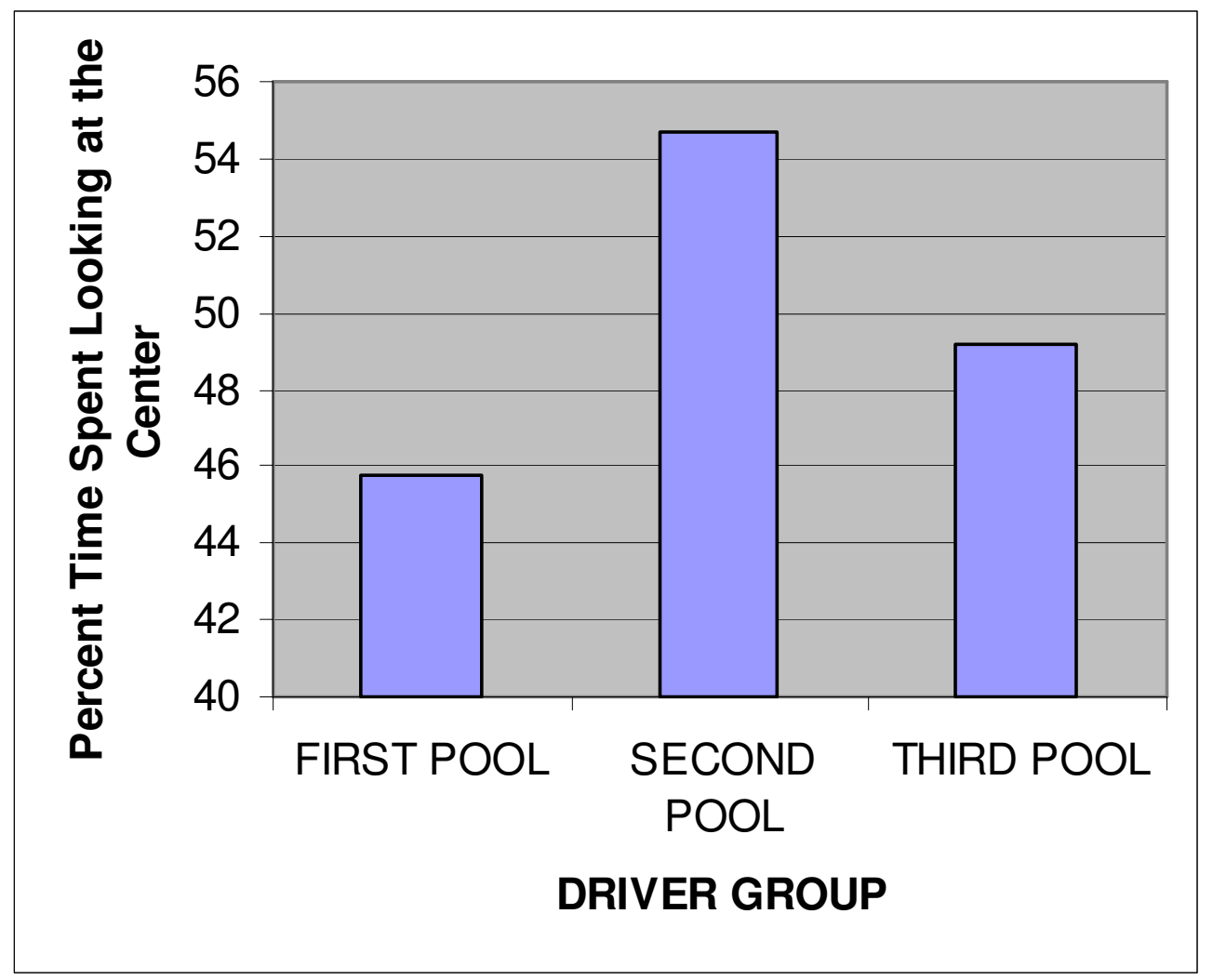

Figure No. 17: Comparison of Percent Time Spent Looking at COR by Driving Experience (Groups 1, 2 and 3)

From the graph, it is evident that the percent time spent looking at the center is higher for group 2 drivers. As mentioned earlier, group 1 drivers are high school students in their driver education class. The lower percentage in group 1 drivers can be due to the fact that 
they are asked by the instructor to look around while making a turn or when at an intersection. The route, in which the high school students drove, though different for almost each driver, had more turns and intersections compared to the route taken by drivers from groups 2 and 3. This is the reason for eliminating the first group from other calculations.

The number of glances made by the high school students was also high as they are asked to look around by the instructor. But, when on a straight stretch of road, high school students were looking only at the COR. The presence of the instructor beside them and their inexperience could deter them from a better scanning of the environment. A few students were being graded in their driving class as the experiment was being carried out. Hence, they were extremely cautious as their driving would influence their grade. 


\section{SUMMARY AND CONCLUSIONS}

This study helps understand the variation in the extent of vehicle operator distraction by driving experience and gender. The main emphasis of the study was made on the visual distractions that drivers involve in a real world scenario. On-road and in-vehicle distractions were held constant for all drivers in the sample as much as possible. These distractions included comparable standard conversations with other passengers in the vehicle, similar traffic conditions, constant traffic control devices and billboards along a pre-established route. In order to test the distraction caused solely by auditory-verbal distractions of a conversation, the distraction from other factors would have to be eliminated. This is not possible in a real road environment. Hence, auditory and verbal distractions were considered along with constant general distracting factors present along the roadway common to all drivers in the study.

Even though no significant difference was observed in total distraction duration and percent time spent looking at the COR by experience level and gender, the mean values of the sample suggest inherent differences between groups. The mean values of the variables for both groups differed, suggesting a higher level of distraction in the less experienced group. A significant statistical difference however, was observed in the number of glances made at the COR. The number was higher for experienced and female drivers. 


\section{Interpretation of Results Based on Driver Experience:}

The mean total distraction duration was found to be higher for drivers with less than one year experience (Group 2). This implies that drivers with less experience can get distracted more easily, i.e. they look continuously away from the COR for more than two seconds more often.

The mean percent time spent looking at the COR was higher for less experienced drivers (Group 2) compared to experienced drivers (Group 3). This did not include the time when drivers were looking at the mirrors. It was observed from the data recorded that experienced drivers in the third group looked at the mirrors more often than the less experienced drivers in the second group. This could be one of the reasons for the reduced percent time spent looking at the COR for experienced drivers.

On the other hand, the number of glances away from the COR was higher for experienced drivers. In other words, experienced drivers (Group 3) looked away from the COR more than the drivers with less than one year of experience (Group 2). Thus, it can be inferred that experienced drivers look for vehicles around them and also observe the roadway environment for any approaching vehicles at driveways and intersections or a situation where their attention is required. Novice drivers lacking experience do not do this as often. 
A comparison between the total distraction duration and percent time spent looking at the roadway provides information to better understand the variation of distraction depending on driver experience. As described earlier in the methodology section, distraction duration is the total time a driver is looking away from the COR for more than two seconds. All these distraction intervals added together is the total distraction duration time. A reduced sample mean of total distraction duration for the experienced drivers, in spite of the reduced percent time spent looking at the center, can be due to the fact that experienced drivers look away from the COR by making quick glances (less than two seconds) and glance back at the COR frequently. That means experienced drivers do not keep looking at something outside the roadway continuously (more than two seconds). Unlike experienced drivers, less experienced drivers in the second group glance at an object or event for a longer duration. It can be said that, even though experienced drivers take more glances and look away from the COR for a longer time, they are less distracted compared to young and novice drivers. The fact that experienced drivers have a higher number of glances away from the COR supports this reasoning.

\section{Interpretation of Results Based on Driver Gender:}

The mean total distraction duration for male drivers was higher than that for female drivers while the mean percent time spent looking at the center was lower for male drivers. Hence, the above sample mean values suggest that male drivers can be more distracted under regular driving conditions (in the absence of additional distracting factors), as they spend less time looking at the COR. The difference though, was not statistically significant. On the other hand, a significant difference was observed in the 
number of glances made away from the COR and female drivers made more glances compared to male drivers. Thus, taking into account the sample mean values of all the distracting factors considered, female drivers looked away from the COR often but glanced back at the roadway more frequently exhibiting, therefore, a better scanning of the roadway. It is important to note that this higher number of glances away from the center also include the glances made while attending secondary tasks such as conversations in the vehicle. It was observed that drivers made glances at the rearview mirror while talking to the passenger in the rear seat. This is due to the fact that female drivers were observed to look at the passengers while conversing with them, during the experiment. A few female drivers did not make a correct assessment of the gap against oncoming traffic while making the unprotected left turn in the drive i.e., the approaching vehicle was observed to be too close to the test vehicle. In addition, most of the female drivers in the sample were also part of the experienced group; a better balance in the numbers of experienced/novice drivers in male and female groups of drivers could provide more accurate conclusions in that respect.

It can be said, from the results obtained and the above discussion, that experienced drivers do not look at the COR continuously for a long time. Instead, they make frequent short glances at the roadside environment and scan the roadside environment. In comparison, less experienced drivers spend more time looking at the COR and when they glance away, they take longer periods of time before they glance back at the road. It was also observed that less experienced drivers made fewer glances at the rear view mirror and side mirrors compared to experienced drivers. This may also indicate a more 
defensive type of driving for experienced drivers and a lack of proper awareness of roadway and traffic conditions for less experienced drivers.

From the above calculations and interpretations it is found that, along with other common factors like roadside advertisements, billboards and traffic, verbal conversations are a major factor contributing to driver distraction. 


\section{RECOMMENDATIONS AND FUTURE RESEARCH}

The study was conducted on a busy state route. This section of roadway has many driveways, roadside advertisements and intersections. Any small distraction on this type of road may lead to a crash. The total distraction duration did not vary for drivers with different experience level or gender. The reason may be the familiarity of the route to all drivers. Studying the driver behavior on an unfamiliar route or by varying the distraction factors can lead to a better understanding of the variation of distraction by experience. The average percent time spent looking at the COR was around 50\% for drivers in both experienced and less experienced groups. Since the route was familiar to all drivers, this most likely reduced the possibility of a crash, but it could be quite different in case of an unfamiliar road. Hence a consideration of the percent time spent looking at the roadway based on familiarity and type of street can lead to a better understanding of the time a driver spends looking at the COR.

It was observed during data collection that the drivers made more glances at the rear view mirror when talking to a person in the rear passenger seat. This increased number of glances away from the roadway can lead to a crash. The total number of glances was higher for the experienced group of drivers. Evaluating the time spent looking away from the COR for each glance can help determine if this higher number was due to distraction, or for a better scanning of the roadway. 
Less experienced drivers made very few glances at the mirrors. It was also observed that few drivers drove above speed limits and less cautiously when taking the un-signaled left turn in the drive while talking to the passenger in the vehicle. Proper traffic control devices and signing at local street intersections is therefore important for reducing the crashes involving young and novice drivers given that their attention concentrates on the COR. The size and location of the signs also play a major role in attracting the attention, particularly of novice drivers. The roadway design is important as well. It should be favorable to the road user and provide a better field of view of adequate section of roadway without confusion.

Many of the new technologies that have been introduced into the driving environment by the vehicle manufacturers, the operators, or advertisers increased the number of distractions a driver is exposed to, both on road and inside the vehicle. While young drivers may be more comfortable using new technologies like GPS, cell phones, etc., it has been established, from past research, that cell phones contribute to distraction; and thus, increase the possibility of crashes. Even though conversations with passengers are said to distract, conversations conducted over cell phones are considered to be more distractive. This is due to the fact that a conversation with a passenger can be stopped when a traffic situation deserves attention. However, this is not the case with cell phones due to obvious reasons. The driver may hold a conversation over the cell phone when his/her attention is needed, but the person on the other side, unaware of the situation might continue talking, which could lead to distraction. It is hence important that novice drivers are aware of the levels of distraction caused by new technologies. Greater public 
awareness of the risks of using these devices while driving and greater enforcement of relevant laws is necessary to help mitigate the number of distraction-related crashes involving young and novice drivers. Some cities in the United States have banned cell phone use while driving or have suggested the use of hands-free devices. A study of the variation in driver distraction by cell phone use can help in developing ways to mitigate the effects of cell phone use while driving.

Further research on the extent of verbal conversations alone and comparing the number of saccades and occlusions made by each driver would give a better understanding of the variation of auditory-verbal distractions with experience. Considering the mental and physical condition of the driver while on the road can help in determining whether the distraction is due to roadside factors or driver factors. 


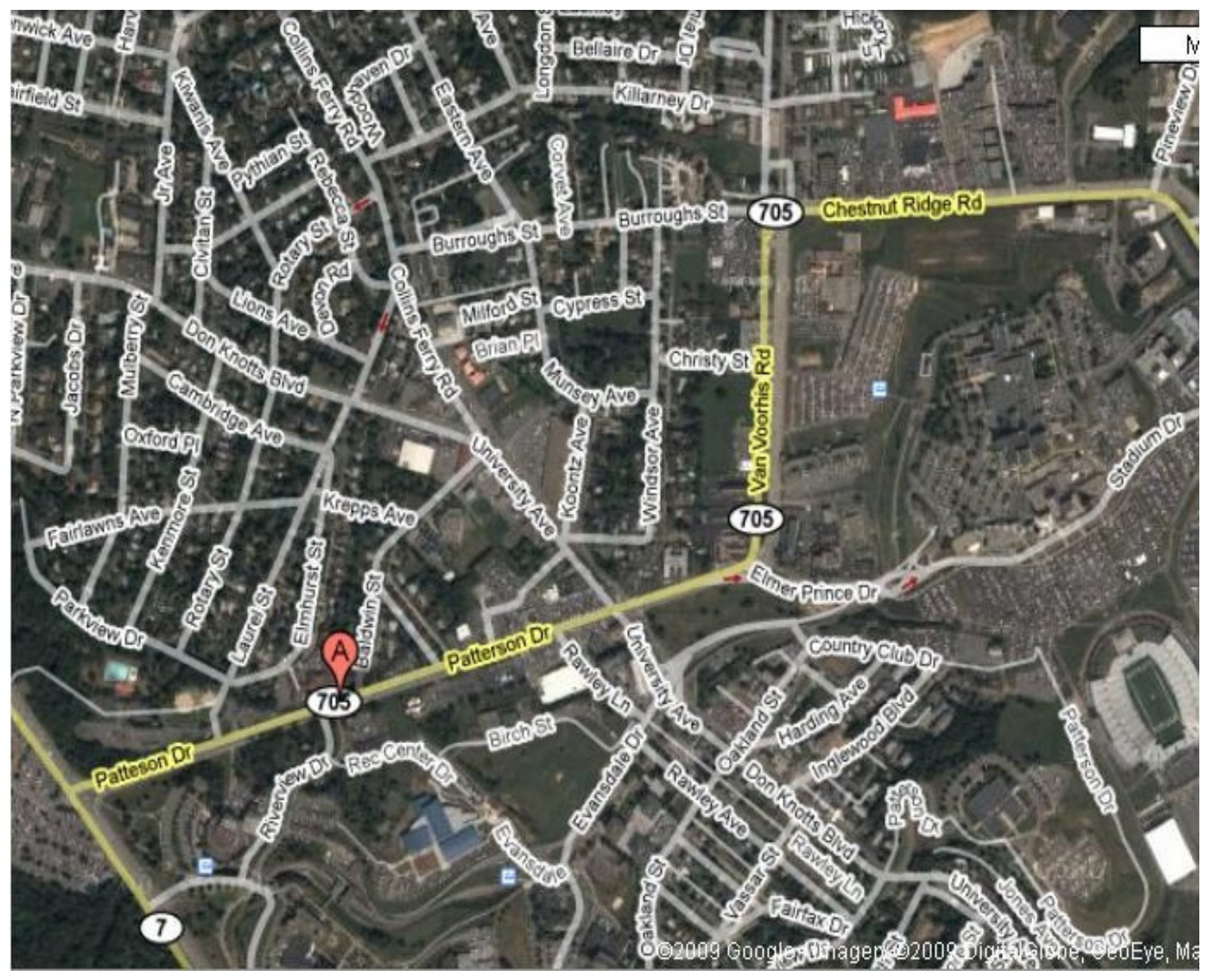

Figure No. 18: Arial view of the roadway section chosen for second and third pool drivers. 


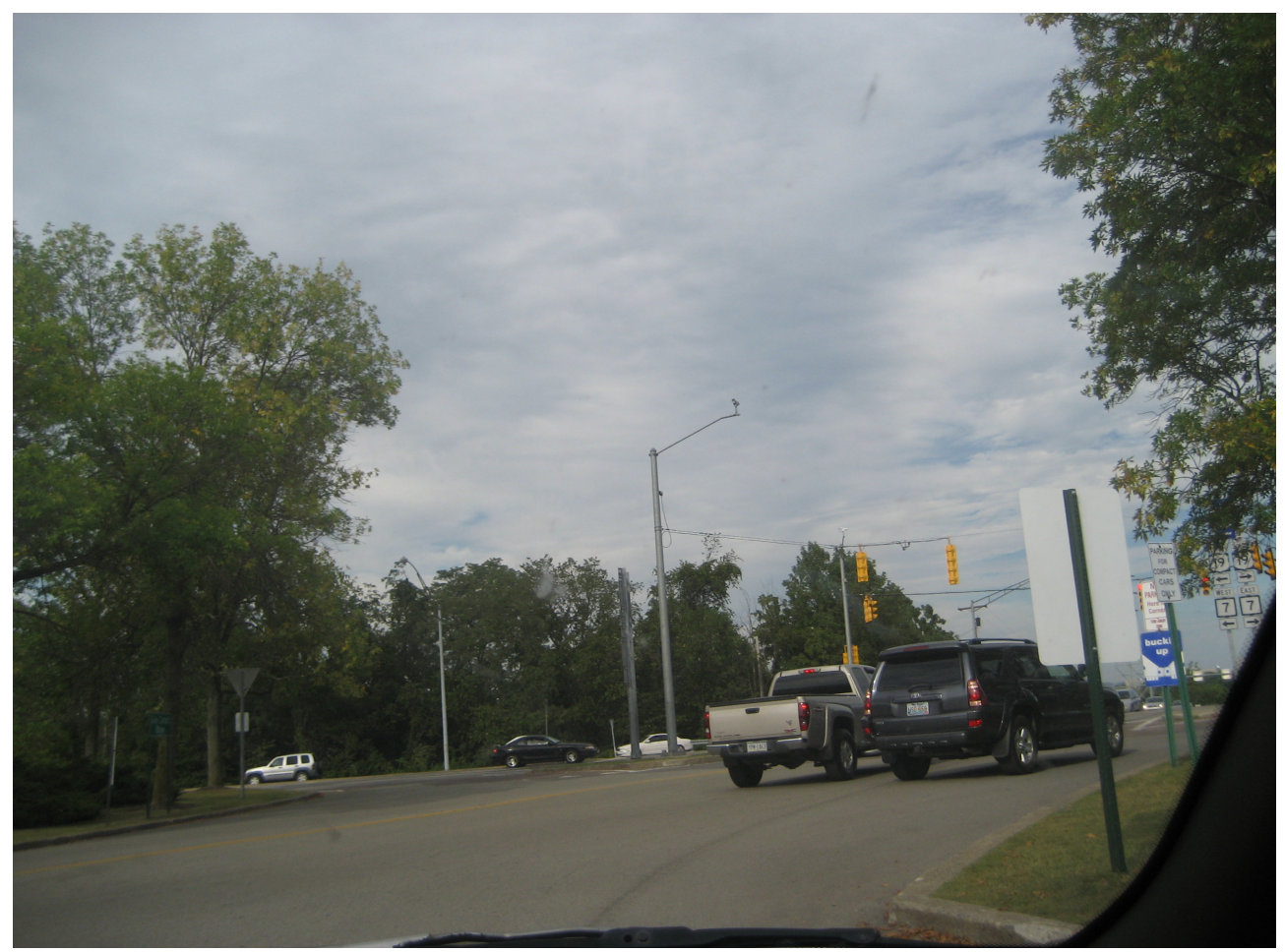

Figure No. 19 : Images showing the roadway conditions prevailing along the section selected

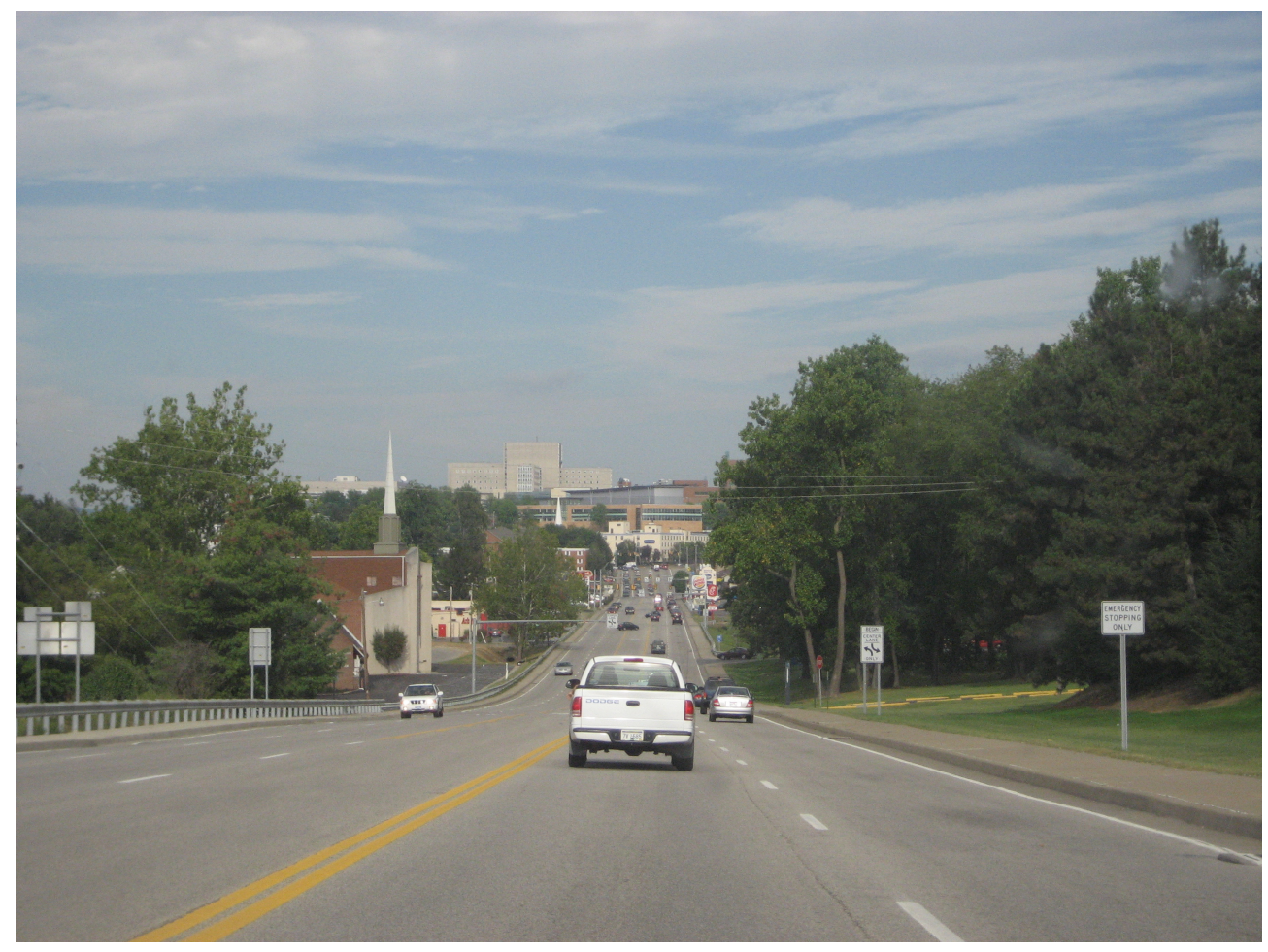

Figure No. 20: Images showing the roadway conditions prevailing along the section selected 


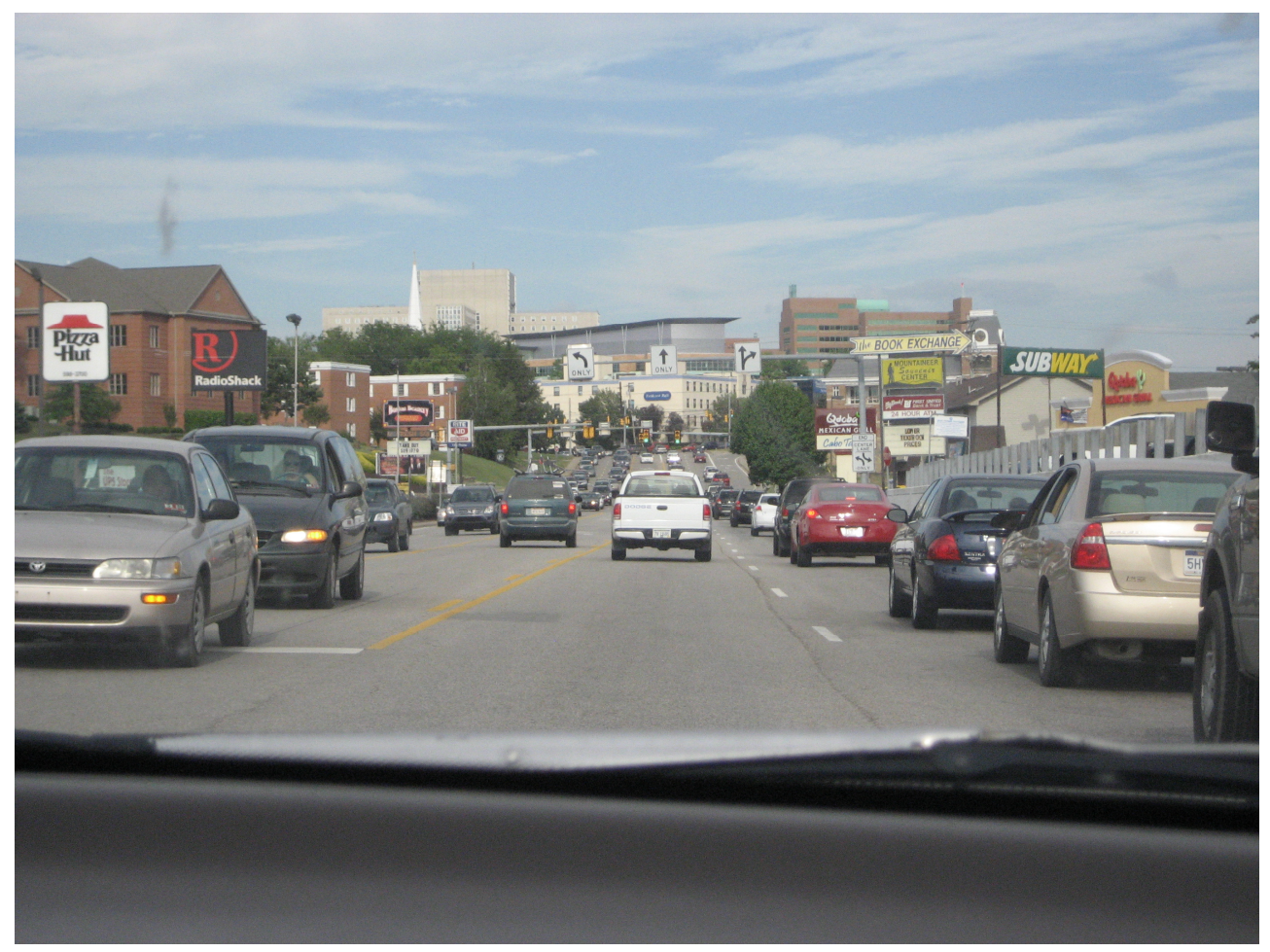

Figure No. 21: Images showing the roadway conditions prevailing along the section selected

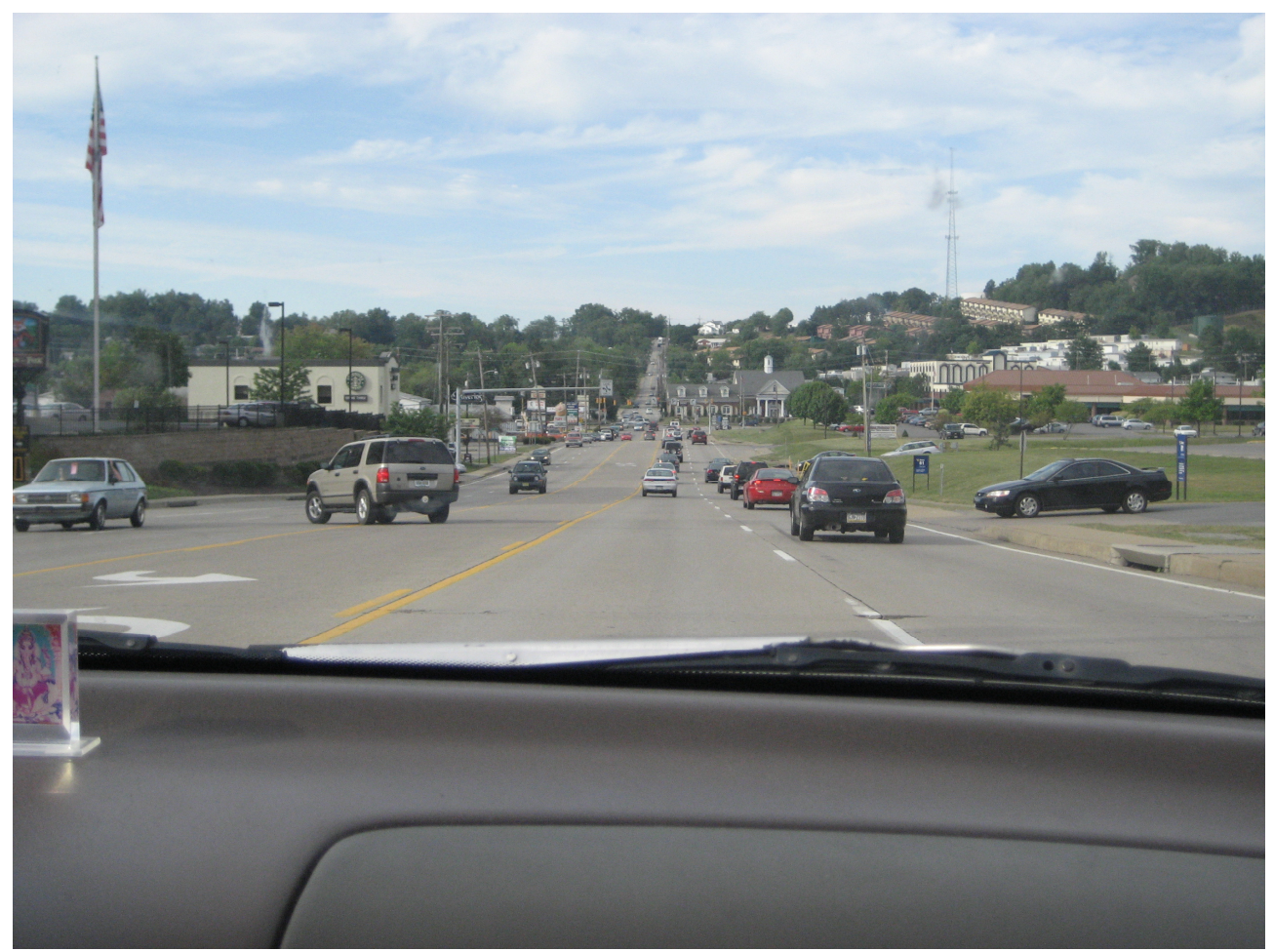

Figure No. 22: Images showing the roadway conditions prevailing along the section selected 


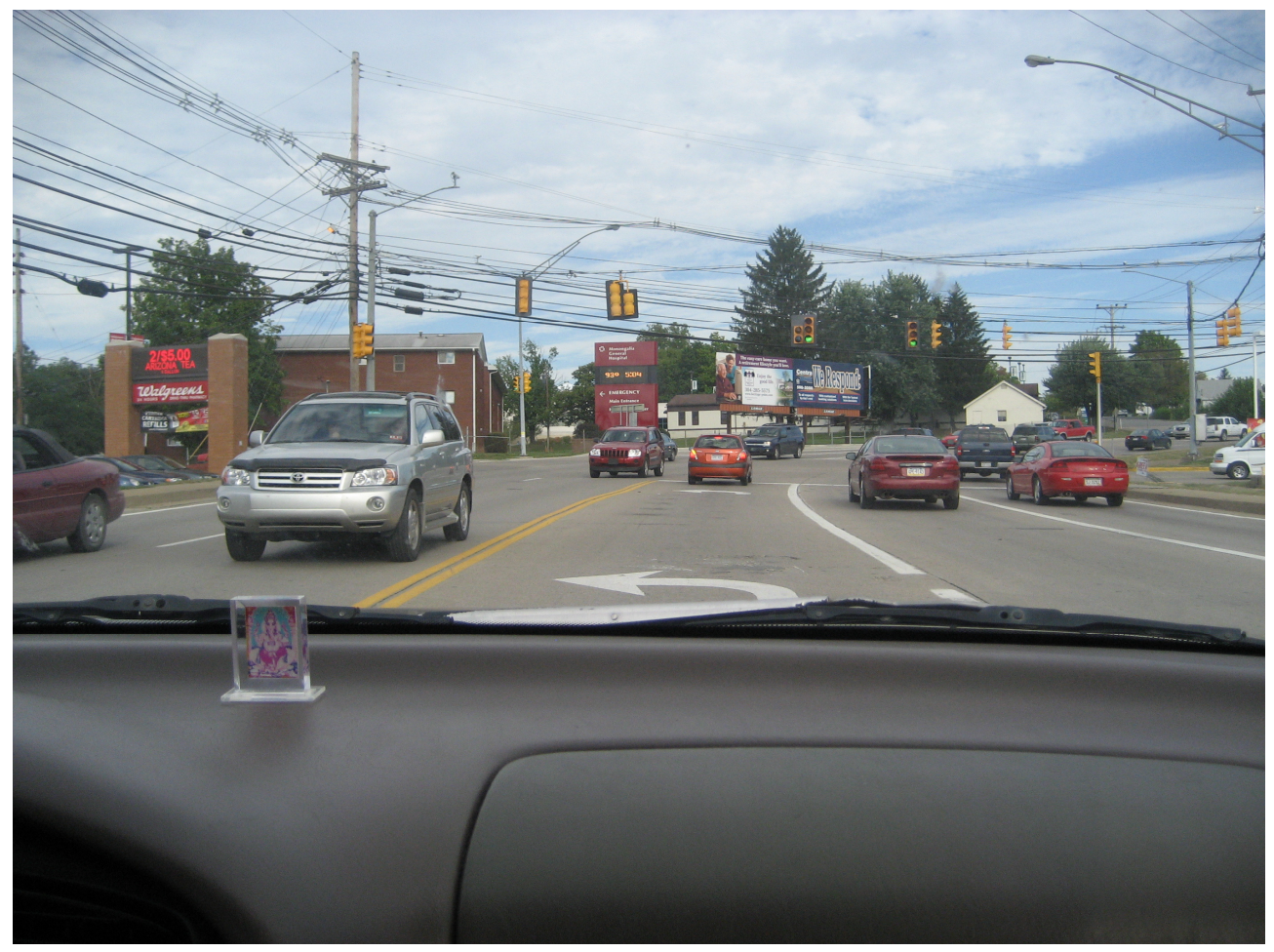

Figure No. 23: Images showing the roadway conditions prevailing along the section selected

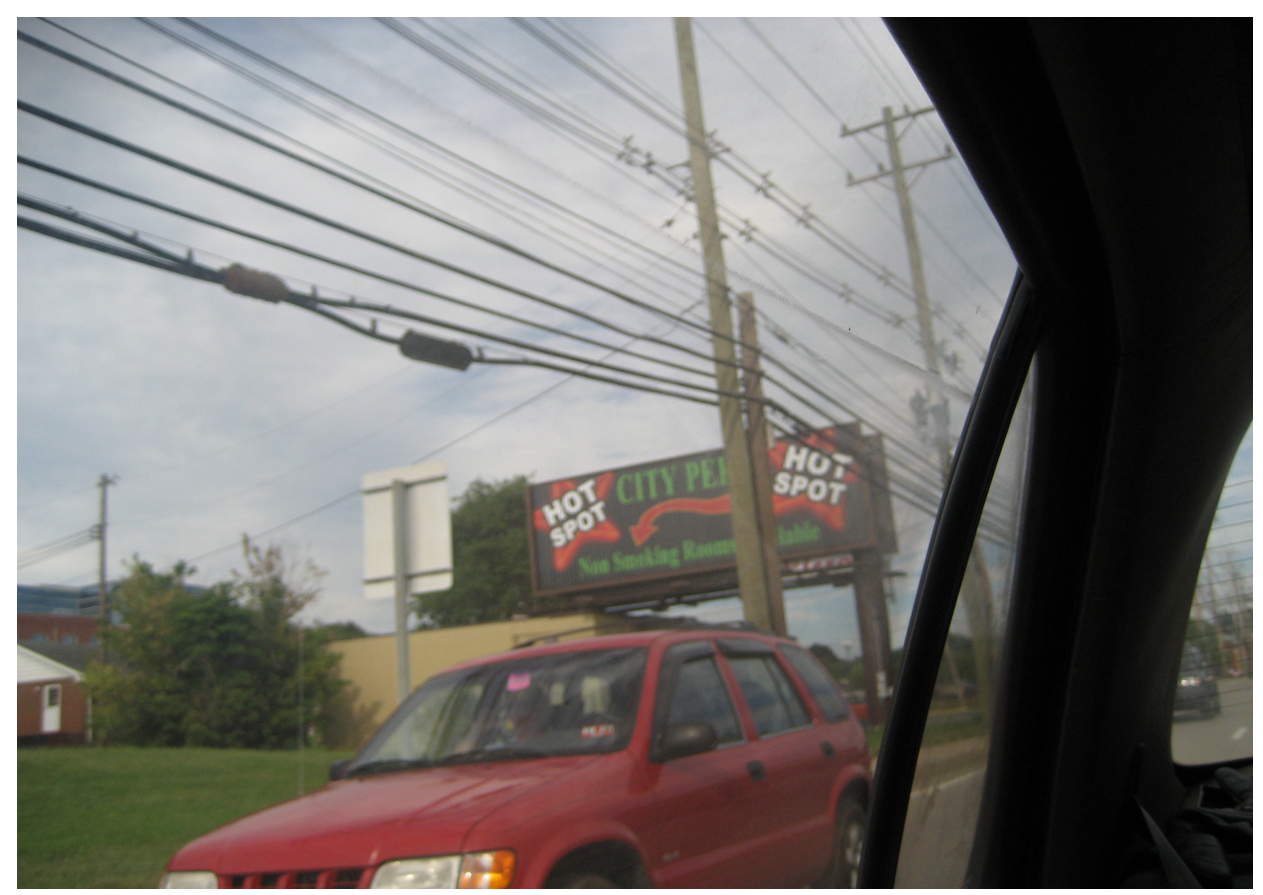

Figure No. 24: Images showing the roadway conditions prevailing along the section selected 


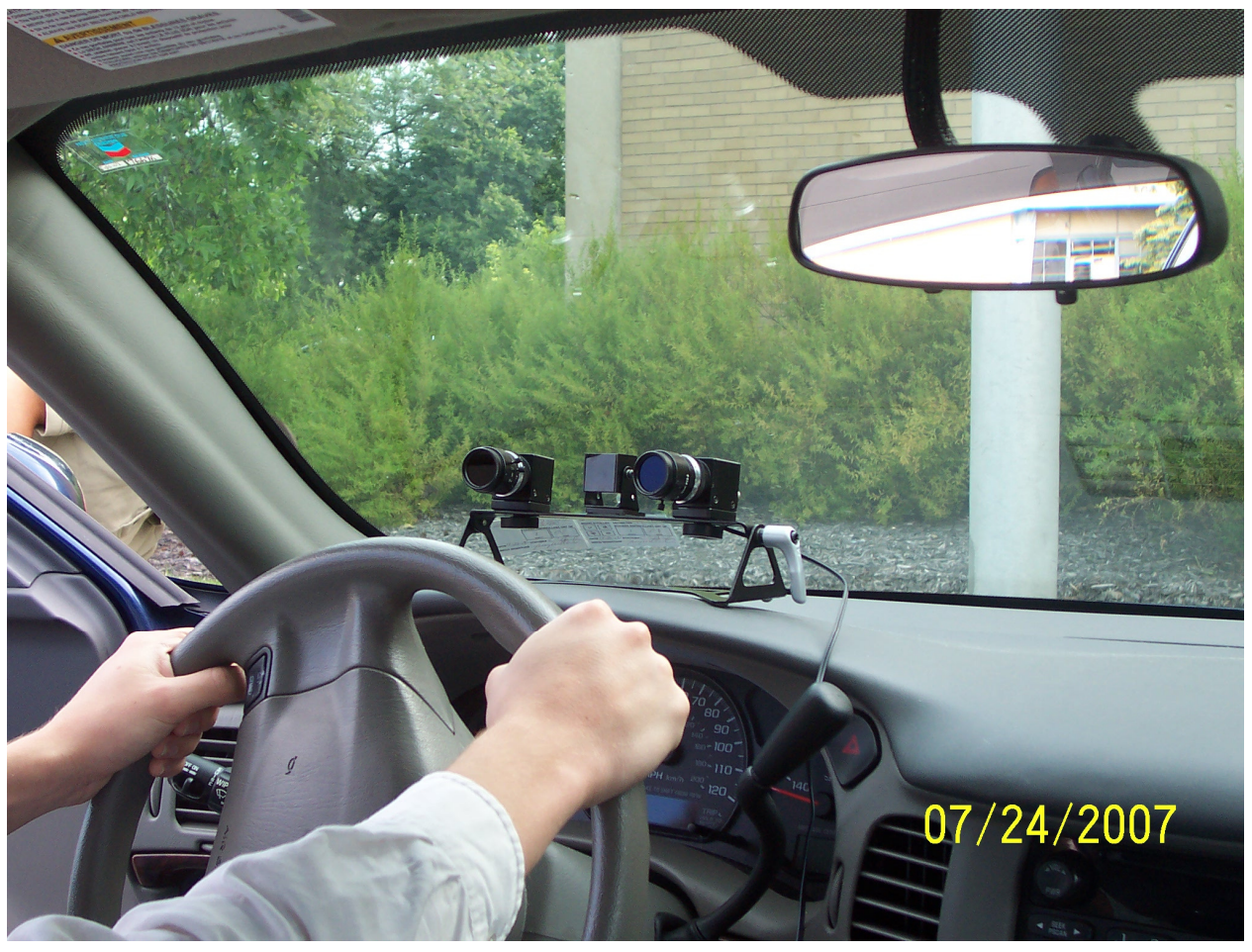

Figure No. 25: Arrangement of Eye tracking system

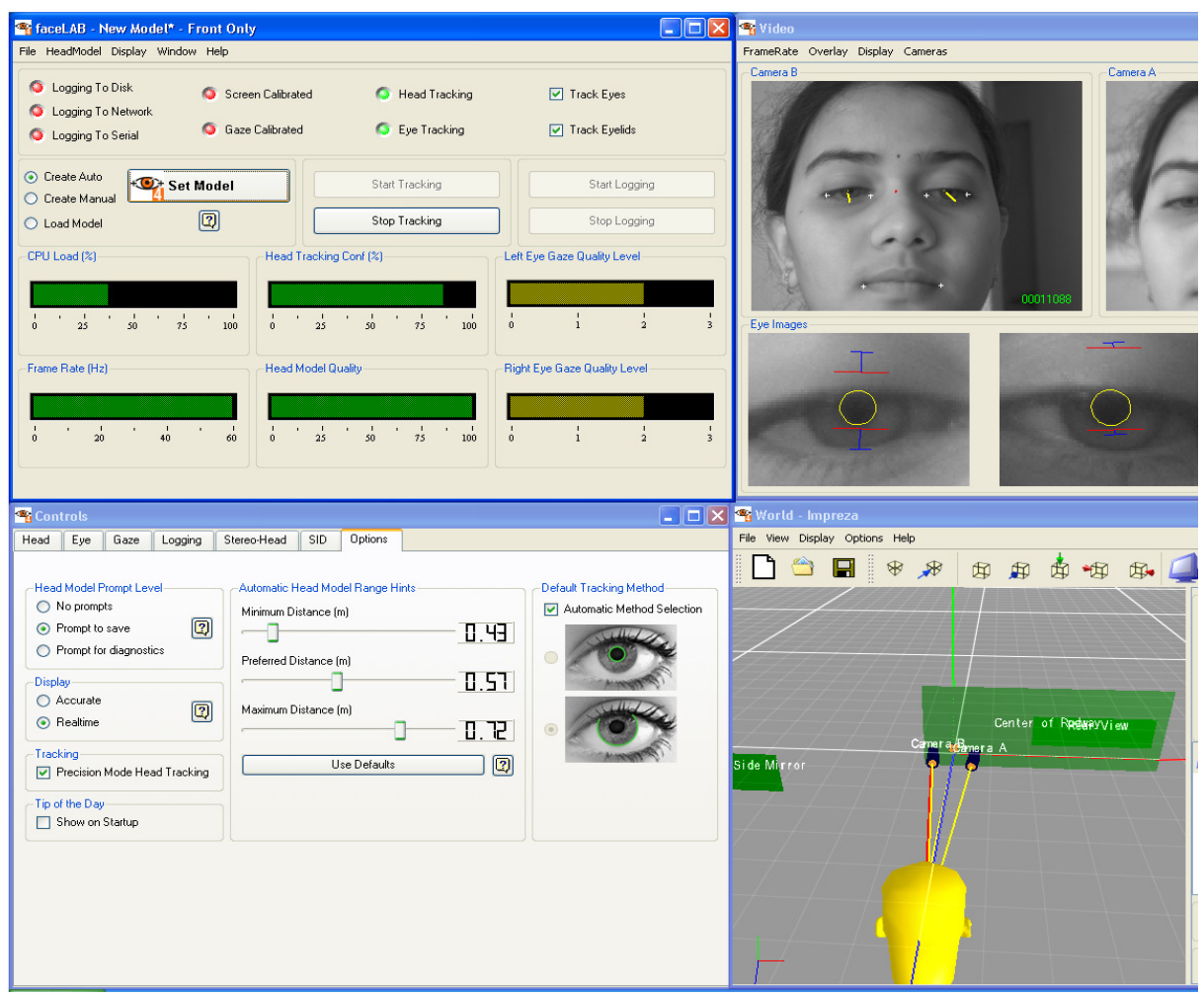

Figure No. 26: face LAB logging window 


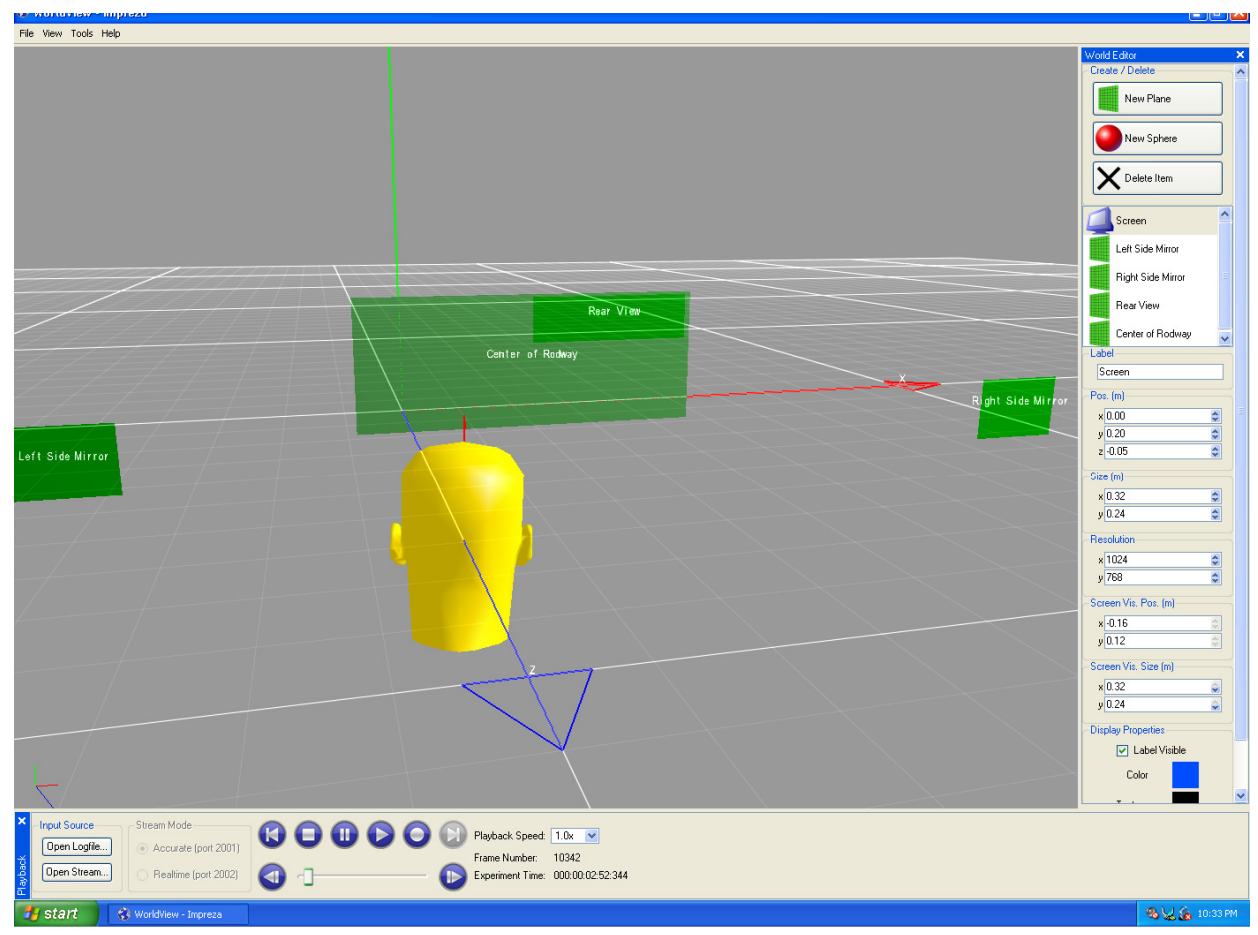

Figure No. 27: WorldView window 


\section{REFERENCES}

1. Young, K., Regan, M., Hammer, M. (2003). Driver Distraction: A Review of the Literature. Monash University Accident Research Center, Report No. 206, November 2003.

2. Schlatter, K., Joseph Pellerito Deborah McAvoy, Jr. and Datta, T. (2006). Assessing Driver Distraction from Cell Phone Use: A simulator-Based Study. Transportation research Record No. 1980, pp. 87-94.

3. Strayer, D., Drews, F. (2004). Profiles in Driver Distraction: Effects of Cell Phone Conversations on Younger and Older Drivers. Human Factors, Vol. 46 No. 4, pp. 640-649.

4. Trent, V.W., et al. (2005). Sensitivity of eye-movement measures to in-vehicle task difficulty. Transportation research. Part F, Traffic psychology and behavior, Vol. 8 No. 2, pp. 167-190.

5. Treat, J.R., Tumbas, N. S., McDonald, S. T., Shinar, D., Hume, R. D., Mayer, R. E., et al. (1977). Tri-level study of the causes of traffic accidents: Final reportexecutive summary (Technical Report DOT HS 805 099). US Washington, DC: Department of Transportation, National Highway Traffic Safety Administration.

6. Lamble, D., Laakso, M., Summala, H. (1999). Detection thresholds in car following situations and peripheral vision: Implications for positioning of visually demanding in-car displays. Ergonomics, Vol. 42 No. 6, pp. 807-815.

7. Rensink, R. A. (2002). Change detection. Annual Review of Psychology. 53, pp. 245-277. 
8. Lee, S. E., Olsen, E. C. B., Morton, B. S. (2006). Eye glance behavior of novice teen and experienced adult drivers. Transportation research board meeting.

9. Cooper, P. J., Zheng, Y. (2002). Turning gap acceptance decision-making: the impact of driver distraction. Journal of safety research, 33, pp. 321-335.

10. Uno, H., Hiramatsu, K. (2000). Effects of auditory distractions on driving behavior during lane change course negotiation: estimation of spare mental capacity as a index of attention distraction. JSAE Review, Vol. 21, No. 2, pp. 219-224.

11. Stutts, J. C., Reinfurt, D. W., Staplin, L., Rodgman, E. A. (2001). The role of driver distraction in crashes. Report prepared for AAA Foundation for traffic safety, Washington, DC. Retrieved 11 November 2008 from: http://www.aaafoundation.org/pdf/distraction.pdf.

12. Hatfield, J., Chamberlain, T. (2008). The effect of audio materials from a rear-seat audiovisual entertainment system or from radio on simulated driving. Transportation research. Part F, Traffic psychology and behavior, Vol. 11, No. 2, pp. 52-60.

13. Lansdown, T. C., Carter, N. B., Kersloot, T. (2002). Primary task disruption from multiple in-vehicle systems. ITS Journal, 7, pp. 151-168.

14. Steven Kass (2007). Effects of Distraction and Experience on Simulation Awareness and Simulated Driving. Transportation Research. Part F, Traffic Psychology and Behavior, Vol. 10, No. 4, pp. 321-329. 
15. David Crundall, Editha Van Loon, Geoffrey Underwood (December 2005). Accident Analysis and Prevention: Attraction and distraction of attention with roadside advertisements.

16. Anttila Virpi (2005). Surrogate In-Vehicle Information Systems and Driver Behavior in an Urban Environment: A Field Study on the Effects of Visual and Cognitive Load. Transportation Research. Part F, Traffic Psychology and Behavior, Vol. 8, No. 2, pp. 121-133.

17. Joanne L. Harbluk, Y. Ian Noy (February 2007). Impact of cognitive distraction on driver visual behavior and vehicle control. Ergonomics Division Road Safety and Motor Vehicle Regulation Directorate.

18. McMonagle A. Traffic accidents and roadside features. Highway Research Board Bulletin, 1952, 55, 38-48.

19. Holohan C., Culler R. and Wilcox B. Effects of visual distraction on reaction time in a simulated traffic environment. Human Factors, 1978, 20, No. 4, 409-413.

20. Sodhi, M., Reimer, B., Llamazares, I. (2002). Glance analysis of driver eye movements to evaluate distraction. Behavior research methods, Instruments and Computers. Vol. 34, No. 4, pp. 529-538.

21. Dean P. Chiang, Aaron M. Brooks, David H. Weir (2004). On the highway measures of driver glance behavior with an example automobile navigation system. Dynamic Research Inc., Torrance, CA.

22. Qiang Ji, Xiaojie Yang (2002). Real-Time Eye, Gaze, and Face Pose Tracking for Monitoring Driver Vigilance. Real-Time Imaging, 8, pp. 357-377.

23. www.seeingmachines.com 
24. Ferguson, S. (2003). Other high risk factors for young drivers-how graduated licensing does, doesn't, or could address them. Journal of safety research, 34, pp. $71-77$.

25. Underwood, G., Crundall, D., Chapman, P. ( 2002). Selective searching while driving: The role of experience in hazard detection and general surveillance. Ergonomics, 45, pp. 1-12.

26. Reimer, B., D’Ambrosio, L., Gilbert, J., Coughlin, J., Biederman, J., Surman, C., Fried, R., Aleardi, M. (2005). Behavior differences in drivers with attention deficit hyperactivity disorder: The driving behavior questionnaire. Accident analysis and prevention, Vol. 37, No. 6, pp. 996-1004.

27. Coughlin, J. (2005). Not your father's auto industry? Aging, the automobile, and the drive for product innovation. Generations, Winder, pp. 38-44.

28. National Transportation Safety Board. Special investigation highway report medical oversight of non-commercial drivers. National Transportation Safety Board Public Meeting, November 92004.

29. Reimer, B., D’Ambrosio, L. A., Coughlin, J. F., Bell, A., Biederman, J. (2006). A secondary analysis of time of day and age effects on simulated driving performance. Transportation research Board Annual Meeting, Washington D.C., January 2006.

30. Treat, J. R. (1980). A study of precrash factors involved in traffic accidents. HRSI Research Review, Vol. 10, pp. 1-35. 
31. Just, M. A., P.A. Carpenter, T. A. Keller, L. Emery, H. Zajac, K. R. Thulborn (2001). Interdependence of non-overlapping cortical systems in dual cognitive tasks. NeuroImage, Vol. 14, pp. 417-426.

32. Rockwell, T. H. (1988). Spare visual capacity in driving-revisited: New empirical results for an old idea. Vision in vehicles II, A.G. Gale et al. editors, Elsevier Science Publishers BV.

33. Zwahlen, H.T. (1988). Safety aspects of cellular telephones in automobiles. (Paper No. 88058). Paper presented at the International Symposium on Automotive Technology and Automation (ISATA), Florence, Italy, May 1988.

34. Ranney, T. A., Mazzae, E., Garrott, R., Goodman, M. J. (2000). National Highway Traffic Safety Administration (NHTSA) Driver Distraction Research: Past, present and future, July 5, 2000.

35. Olsson, S., Burns, P. C. (2000). Measuring driver visual distraction with a peripheral detection task. Driver Distraction Internet Forum. http://wwwnrd.nhtsa.dot.gov/departments/Human\%20Factors/driver-distraction/PDF/6.PDF. Accessed on 06-08-2009.

36. Martens, M. H., van Winsum, W. (2000). Measuring distraction: the peripheral detection task. Distraction Internet Forum. $\underline{\text { http://www- }}$ nrd.nhtsa.dot.gov/departments/Human\%20Factors/driver-

distraction/PDF/34.PDF. Accessed on 06-08-2009.

37. Greenberg, J., Tijerina, L., Curry, R., Artz, B., Cathey, L., Grant, P., et al. (2003). Evaluation of driver distraction using an event detection paradigm. Journal of the Transportation Research Board, 1843, pp. 1-9. 
38. Zwahlen, H. T., Adams, C. C., Jr., de Bald, D. P. (1988). Safety aspects of CRT touch panel controls in automobiles. In A. G. Gale, et al. (Eds.), Vision in vehicles II, pp. 335-344. The Netherlands: North Holland.

39. Rizzo, M., Stierman, L., Skaar, N., Dawson, J. D., Anderson, S. W., Vecera, S. P. (2004). Effects of a controlled auditory-verbal distraction task on older driver vehicle control. Transportation Research Record: Journal of the Transportation Research Board, No. 1865, TRB, National Research Council, Washington, D.C., pp. 1-6.

40. Sodhi, M., Reimer, B., Cohen, J. L., Vastenburg, E., Kaars, B., Kirschenbaum, S. (2002). On-road driver eye-movement tracking using head-mounted devices. Eye tracking research and application. Proceedings of the 2002 symposium on eye tracking research and applications. Session: Systems \& applications. Pp. 61-68.

41. Bittner Jr., A. C., Simsek, O., Levison, W. H., Campbell, J. L. (2002). On-road vs. simulator data in driver model development: driver performance model (DPM) experience. Paper No. 02-4103, $81^{\text {st }}$ TRB Annual Meeting, Washington, DC, January 2002.

42. Meister, D. (1999). The History of Human Factors. Lawrence Erlbaum Associates, Mahwah, NJ.

43. Green, P. (1995). Automotive Techniques. In J. Weimer (Ed.), Research Techniques in human engineering, Prentice Hall, Englewood Cliffs, NJ, pp. 165208.

44. Meister, D. (1995). Simulation and Modeling. In J.R. Wilson and E.N. Corlett (Eds.), Evaluation of Human Work, $2^{\text {nd }}$ ed. Taylor and Francis, Bristol, PA. 
45. Wierwille, W. W., Tijerina, L. (1996). An analysis of driving accident narratives as a means of determining problems caused by in-vehicle visual allocation and visual workload. In A. G. Gale et al. (Eds.), Vision in Vehicles V. Amsterdam: North-Holland.

46. McPhee, L. C., Scialfa, C. T., Dennis, W. M., Ho, G., Caird, J. K. (2004). Age differences in visual research for traffic signs during a simulated conversation. Human Factors, Vol. 46, No. 4, pp. 674-685.

47. Merat, N., Anttila, V., Luoma, J. (2005). Comparing the driving performance of average and older drivers: The effects of surrogate in-vehicle information systems. Transportation research. Part F, Traffic psychology and behavior, Vol. 8, No. 2, pp. 147-166.

48. Liu, B. -S., Lee, Y. -H. (2006). In-vehicle workload assessment: Effects of traffic situations and cellular telephone use. Journal of Safety Research, 37, pp. 99-105.

49. Lee, Y.-C., Lee, J. D., Boyle, L. N. (2007), Visual attention in driving: The effects of cognitive load and visual disruption. Human Factors, 49, pp. 721-733. 
Appendix: A1

\section{W. WestVirginiaUniversity. Office of Research Compliance}

\section{Expedited - IRB Protocol - Approval}

To: Medellin, Leonel

From: WVU Office of Research Compliance

Date: Thursday, May 08, 2008

Subject: No action required

Tracking \#: $\mathrm{H}-20902$

Title: Assessment of Driver Distraction vs. Driving Experience

The research study referenced above was reviewed by The West Virginia

University [! boardname] Board for expedited review on 5/8/2008; on 05/08/2008, Barbara White approved this study via expedited review procedures.

While no action is required on your part, the IRB made the following findings:

Please adhere to the requirements for disclosure of data as outlined in your Data Use Agreement. If you have questions please refer to the IRB website.

The following documents have been approved and validated for use in this study and are available in the BRAAN system:

Consent Form

Parental Consent Form

Assent Form

Flyer

Board Designee: White, Barbara

Thank you. 
Letter Sent By: White, Barbara, 5/8/2008 11:31 AM

Once you begin your human subject research the following regulations apply:

1. Unanticipated or serious adverse events/side effects encountered in this research study must be reported to the IRB within five (5) days.

2. Any modifications to the study protocol or informed consent form must be reviewed and approved by the IRB prior to implementation.

3. You may not use a modified informed consent form until it has been approved and validated by the IRB. 


\section{Appendix: A2}

MONONGACIA COUNTY SCHOOLS

13 South High Street, Morgantown, WV 2650 Phone 304-291-9210 Fax 304-291-3015

SUPERINTENDENT

Frank D. Devono
BOARD OF EDUCATION

Nancy A. Walker, President - Joseph C. Staller, Vice -President Steplien L. Cook - Dr. Barbara L. Parsons - Dr. Clarence IVlarve $y, y$,

April 23, 2008

Dr. Leonel Medellin

Dep. of Civil \& Environmental Eng.

West Virginia University

P.O. Box 6103

Morgantown, WV 26506-6103

Dear Dr. Medellin,

We have considered the information we received from you regarding the study on Driver"s Distraction on young novice driving students. From your description of the project, we understand that the required equiprnent (two small cameras) will be placed on the dashboard without any harm to the vehicle and it does not represent any additional distraction to the drivers.

The instructor should be present at all times in the car along with the students while driving and one member of your team may be in the back seat with a laptop collecting the information you need. We believe that the analysis of this information will be useful given the benefits it will bring to understand distraction in young adult's while driving. Only de-identified data should be collected and the video should be destroyed once the study is finished.

We consider that the project does not expose students to any additional risks, hence we give our permi.ssion to use Driver Education high school smdents while taking their usual driving classes as subjects of the study, once the students parenta] consent has boen provided.

Sincerely,

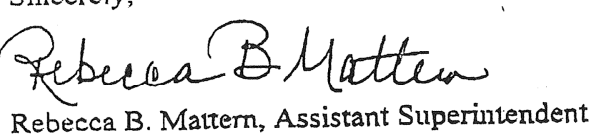




\section{Appendix: A3}
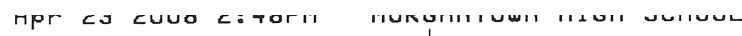

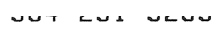

$r \cdot r$

MORGANTOWN HIGH SCHOOL

109 Wilson Avenue • Morgantown, West Virginia 26501

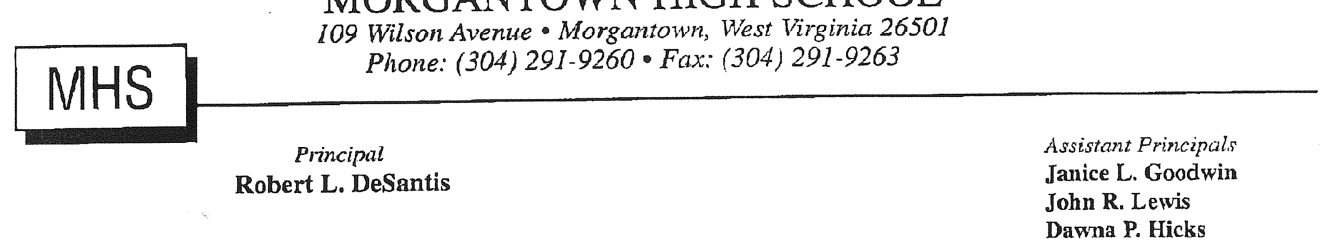

Dr. Leonel Medellin

Dep. of Civil \& Environmental Eng.

West Virginia University

P.O. Box 6103

Morgantown, WV 26506-6103

Dear Dr. Medellin,

Morgantown High School has considered the information we received from you regarding the study on Driver's Distraction on young novice driving students. From your description of the project, we understand that the required two small cameras will be placed on the dashboard without any harm to the vehicle and it does not present any additional distraction to the drivers.

The instructor must be present at all times in the car along with the students while driving and one member of your team may be in the back seat with a laptop collecting the information you need. Only de-identified data should be collected and the video should be destroyed once the study is completed.

We consider that the project does not expose students to any additional risk, hence we give our permission to use our Driver Education students while taking their usual driving classes as subjects of the study, once the students parental consent has been provided.

Sincerely,

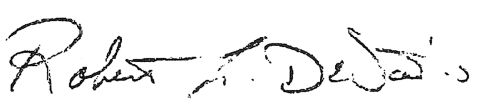

Robert L. DeSantis 


\section{Appendix: A4}

\section{DRAFT LETTER}

Dr. Leonel Medellin

Dep. of Civil \& Environmental Eng.

West Virginia University

P.O. Box 6103

Morgantown, WV 26506-6103

Dear Dr. Medellin,

We have considered the information we received from you regarding the study on Driver's Distraction on young novice driving students. From your description of the project, we understand that the required equipment (two small cameras) will be placed on the dashboard without any harm to the vehicle and it does not represent any additional distraction to the drivers.

The instructor should be present at all times in the car along with the students while driving and one member of your team may be in the back seat with a laptop collecting the information you need. We believe that the analysis of this information will be useful given the benefits it will bring to understand distraction in young adults while driving. Only de-identified data should be collected and the video should be destroyed once the study is finished.

We consider that the project does not expose students to any additional risks, hence we give our permission to use Driver Education high school students while taking their usual driving classes as subjects of the study, once the students parental consent has been provided.

Sincerely,

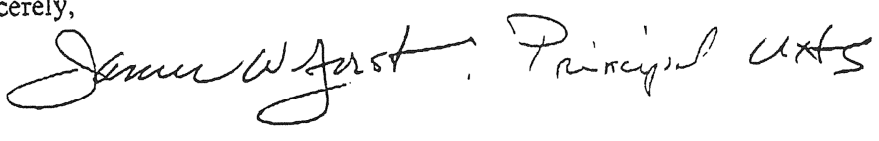




\title{
Appendix: A5
}

\section{WestVirginiaUniversity.}

Office of Research Compliance

\section{PARENTAL OR GUARDIAN CONSENT AND INFORMATION FORM}

\author{
OMR-Parental Consent
}

Principal Investigator: Medellin, Leonel

Department: ENGINEERING - Civil

Tracking Number: $\quad \mathrm{H}-20902$

Study Title:

Assessment of Driver Distraction vs. Driving Experience

Co-Investigator(s):

Akuraju, Nagaanupama

\section{Sponsor}

Mid-Atlantic Universities Transportation Center

\section{Contact Persons}

In the event your child experiences any side effects related to this research, you should contact Dr. Leonel Medellin at 304/293-3031 ext 2659.

If you have any questions, concerns, or complaints about this research, you can contact Dr. Medellin.

For information regarding your rights as a research subject, you may contact the Office of Research Compliance at 304/293-7073.

Introduction

You, have been asked to allow your child to participate in this study, which has been explained to you in a letter and to your child by Dr. Leonel Medellin and/or Graduate Assistant Nagaanupama Akuraju. This study is being conducted by Dr. Medellin in the Department of Civil and Environmental Engineering at West Virginia University sponsored by the Mid-Atlantic Universities

\begin{tabular}{lllll}
\hline Tracking a: & H-20902 & Page 1 of 4 & \\
Approved On: & $05 / 08 / 2008$ & & Inltuals & \\
Valid Through: & $05 / 07 / 2009$ & & \\
Last Amended: & N/A & &
\end{tabular}


Transportation Center. This research is being conducted to fulfill the requirements for a master 's thesis in the Department of Civil and Environmental Engineering at West Virginia University, under the supervision of Dr. David R. Martinelli.

\section{Purposes of the Study}

The purpose of the study is to learn more about drivers' distraction in relation to driving experience. WVU expects to enroll approximately thirty inexperienced subjects and thirty experienced subjects; a total of approximately sixty subjects at all sites are expected to participate in this study.

\section{Description of Procedures}

This study involves the collection of data while driving using two small cameras on the dashboard and eye-tracking software and will take approximately 30 minutes for your child to complete. Your child will be asked to fill out a brief questionnaire regarding basic demographic data (age and gender) and driving experience. This will take approximately one minute. Your child does not have to answer all the questions. You will have the opportunity to see the questionnaire before signing this consent form. The study will be performed while driving familiar routes, (in your child's case, during the Driver Education class). Approximately sixty subjects are expected to participate in this study.

\section{Risks and Discomforts}

There are no known or expected risks to your child from participating in this study, except for the mild discomfort from being observed.

\section{Alternatives}

Your child does not have to participate in this study.

Alternatives that could be considered in your child 's case include not participating in the study.

\section{Benefits}

Your child may not receive any direct benefit from this study. The

\begin{tabular}{lll}
\hline Tracking f: & $\mathrm{H}-20902$ & Page 2 of 4 \\
Approved On: & $05 / 08 / 2008$ & \\
Valid Through: & $05 / 07 / 2009$ &
\end{tabular}


Tracking a: $\quad$ H-20902

knowledge gained from this study may eventually benefit society.

Financial Considerations

No payments will be made for participating in the study.

\section{Confidentiality}

Any information about your child that is obtained as a result of

participation in this research will be kept as confidential as legally possible. Your child's research records and test results, just like hospital records, may be subpoenaed by court order or may be inspected by federal regulatory authorities without your additional consent. In addition, there are certain instances where the researcher is legally required to give information to the appropriate authorities. These would include behavior that is imminently dangerous to your child. Videotapes will be kept locked up and will be destroyed as soon as possible after the research is finished. In any publications that result from this research, neither your child 's name nor any information from which your child might be identified will be published without your consent.

\section{Voluntary Participation}

Participation in this study is voluntary. You or your child may refuse to participate in this study. You or your child may withdraw from this study at any time. Refusal to participate or withdrawal will not affect your child 's class standing or grades and will involve no penalty to you or your child. In the event new information becomes available that may affect your willingness to allow your child to participate in this study, this information will be given to you so that you can make an informed decision about whether or not to continue your child's participation. You have been given the opportunity to ask questions about the research, and have received answers concerning areas you did not understand.

\begin{tabular}{lll}
\hline Tracking t: & H-20902 & Page 3 of 4 \\
Approved On: & $05 / 08 / 2008$ & \\
Valid Through: & $05 / 07 / 2009$ \\
Last Amended: & N/A
\end{tabular}

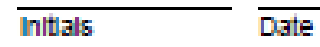


Upon signing this form, you will receive a copy.

I willingly consent to allow my child to participate in this research.

Signature of Parent or Guardian

The parent/guardian has had the opportunity to have questions addressed. The parent/guardian willingly agrees to allow his/her child to be in the study.

\begin{tabular}{|c|c|c|}
\hline Tracking \&: & $\mathrm{H}-20902$ & Page 4 of 4 \\
\hline Approved On: & $05 / 08 / 2008$ & \\
\hline Valid Through: & $05 / 07 / 2009$ & \\
\hline Last Amended: & $\mathrm{N} / \mathrm{A}$ & \\
\hline
\end{tabular}




\section{Appendix: A6}

\section{WestVirginiaUniversity}

Office of Research Compliance

\section{ASSENT FORM}

OMR-Assent

Principal Investigator: Medellin, Leonel

Department: $\quad$ ENGINEERING - Civil

Tracking Number: $\quad \mathrm{H}-20902$

Study Title:

Assessment of Driver Distraction vs. Driving Experience

Co-Investigator(s):

Akuraju, Nagaanupama,

Sponsor

Nid-Atlantic Universities Transportation Center

\section{Contact Persons}

If you have any questions, concerns, or complaints about this research, you can contact Dr. Leonel Medellin at 304/293-3031 ext 2659.

For information regarding your rights as a research subject, you may contact the Office of Researcl. Compliance at 304/293-7073.

\section{Introduction}

You, have been asked to be in this research sludy, which has been explained lo you in a leller and by Dr. Leurel Nedellin and/or Graduate Assistant Nagaanupama Akuraju.

\section{Purposes of the Study}

You have been told that the purpose of this study is to learn more about drivers' distraction in relation to driving experience.

\section{Description of Procedures}

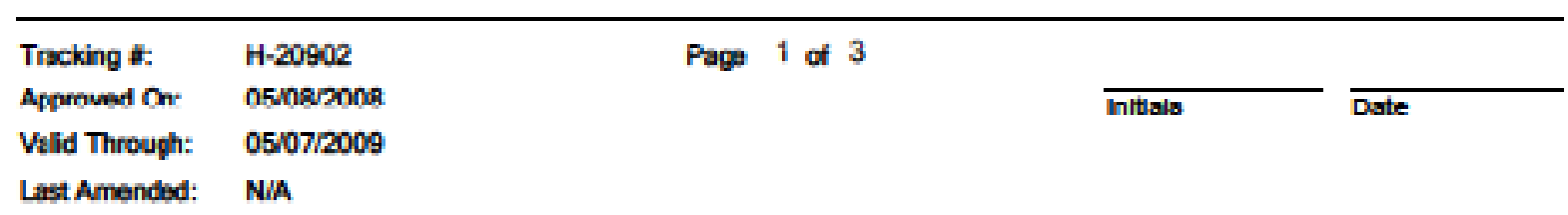


This research study will be done during your regular driver education class, while driving some streets in Morgantown. You will be asked to come as usual to your class. You will be asked some questions (age, gender, and driving experience). It will take about one minute for you to answer the questions. You may see the questions before signing this page. You do not have to answer all of the questions.

\section{Discomforts}

You will be videotaped while driving. This will allow us to measure distraction using special computer software. You may feel some discomfort from being observed and taped.

\section{Benefits}

This study may not help you, but what we learn from the study may help other people.

\section{Confidentiality}

The videotapes will be destroyed upon completion of the study. We promise that anything we learn about you in this study will be kept as secret as possible.

\section{Voluntary Participation}

You do not have to do this and you can quit at any time. No one will be mad at you if you refuse to do this or if you decide to quit. You have been allowed to ask questions about the research, and all of your questions were answered.

\begin{tabular}{|c|c|c|}
\hline Tracking at: & H-20902 & Page 2 of 3 \\
\hline Approved On: & $05 / 08 / 2008$ & \\
\hline Valid Through: & $05 / 07 / 2009$ & \\
\hline 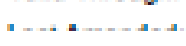 & nu & \\
\hline
\end{tabular}


I willingly agree to be in this research.

Signature of Subject

Printed Name

Date

Time

The child has had the opportunity to have questions addressed. The child willingly agrees to be in the study.

Signature of Investigator or

Printed Name

Date

Co-Investigator

$\begin{array}{lll}\text { Tracking a: } & \mathrm{H}-20902 & \text { Page } 3 \text { of } 3 \\ \text { Approved On: } & 05 / 08 / 2008 & \\ \text { Valid Through: } & 05 / 07 / 2009 & \\ \text { I ast Amanded. } & \text { N/A }\end{array}$


Appendix: A7

\section{WestVirginiaUniversity. \\ Office of Research Compliance}

\section{CONSENT AND INFORMATION FORM}

OMR ICF - DRVR

Principal Investigator: Medellin, Leonel

Department: ENGINEERING - Civil

Tracking Number: $\quad \mathrm{H}-20902$

Study Title:

Assessment of Driver Distraction vs. Driving Experience

Co-Investigator(s):

Akuraju, Nagaanupama

\section{Sponsor}

Mid-Atlantic Universities Transportation Center

\section{Contact Persons}

If you have any questions, concerns, or complaints about this research, you can contact Dr. Leonel Medellin at 304/293-3031 ext 2659.

For information regarding your rights as a research subject, you may contact the Office of Research Compliance at 304/293-7073.

\section{Introduction}

You, have been asked to participate in this research study, which has been explained to you in a letter and by $\mathrm{Dr}$. Leonel Medellin and/or Graduate Assistant Nagaanupama Akuraju. This study is being conducted by Dr. Medellin in the Department of Civil and Environmental Engineering at West Virginia University and is sponsored by the Mid-Atlantic Universities Transportation Center. This research is being conducted to fulfill the requirements for a master's thesis in the Department of Civil and Environmental Engineering at West Virginia University, under the supervision of Dr. David R. Martinelli.

\begin{tabular}{|c|c|c|}
\hline Tracking a: & H-20902 & Page 1 of 4 \\
\hline Approved On: & $05 / 08 / 2008$ & \\
\hline Valid Through: & $05 / 07 / 2009$ & \\
\hline Last Amended: & $N / A$ & \\
\hline
\end{tabular}

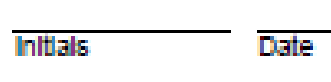




\section{Purposes of the Study}

The purpose of this study is to learn more about drivers distraction in relation to driving experience. WVU expects to enroll approximately thirty inexperienced subjects and thirty experienced subjects; a total of approximately sixty subjects at all sites are expected to participate in this study.

\section{Description of Procedures}

This study involves the collection of data while driving using two small cameras on the dashboard and eye-tracking software and will take approximately 30 minutes for you to complete. You will be asked to fill out a brief questionnaire regarding basic demographic data (age and gender) and driving experience. This will take approximately one minute. You do not have to answer all the questions. You will have the opportunity to see the questionnaire before signing this consent form.

\section{Risks and Discomforts}

There are no known or expected risks from participating in this study, except for the mild discomfort from being observed.

\section{Alternatives}

You do not have to participate in this study.

Alternatives that could be considered in your case include not participating in the study.

\section{Benefits}

You may not receive any direct benefit from this study. The knowledge gained from this study may eventually benefit society.

\section{Financial Considerations}

There are no special fees or rewards for participating in this study.

\section{Confidentiality}

\begin{tabular}{lll}
\hline Tracking a: & H-20902 & Page 2 of 4 \\
Approved On: & $05 / 08 / 2008$ & \\
Valid Through: & $05 / 07 / 2009$ & \\
Last Amended: & N/A
\end{tabular}


Tracking f: $\quad \mathrm{H}-20902$

Any information about you that is obtained as a result of your participation in this research will be kept as confidential as legally possible. Your research records and test results, just like hospital records, may be subpoenaed by court order or may be inspected by federal regulatory authorities without your additional consent. In addition, there are certain instances where the researcher is legally required to give information to the appropriate authorities. These would include information about behavior that is imminently dangerous to you or to others. Videotapes will be kept locked up and will be destroyed as soon as possible after the research is finished. In any publications that result from this research, neither your name nor any information from which you might be identified will be published without your consent.

\section{Voluntary Participation}

Participation in this study is voluntary. You are free to withdraw your consent to participate in this study at any time. Refusal to participate or withdrawal will not affect your employee status at West Virginia University or your class standing or grades and will involve no penalty to you. In the event new information becomes available that may affect your willingness to participate in this study, this information will be given to you so that you can make an informed decision about whether or not to continue your participation. You have been given the opportunity to ask questions about the research, and you have received answers concerning areas you did not understand.

$\begin{array}{lll}\text { Tracking a: } & \text { H-20902 } & \text { Page } 3 \text { of } 4 \\ \text { Approved On: } & 05 / 08 / 2008 & \\ \text { Valid Through: } & 05 / 07 / 2009 \\ \text { Last Amended: } & \text { N/A }\end{array}$

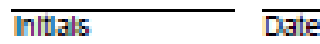


Upon signing this form, you will receive a copy.

I willingly consent to participate in this research.

Signature of Subject or

Subjects Legal Representative

The participant has had the opportunity to have questions addressed. The participant willingly agrees to be in the study.

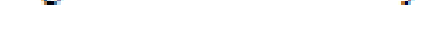

